NBER WORKING PAPER SERIES

\title{
A THEORY OF SMALL CAMPAIGN CONTRIBUTIONS
}

\author{
Laurent Bouton \\ Micael Castanheira \\ Allan Drazen \\ Working Paper 24413 \\ http://www.nber.org/papers/w24413 \\ NATIONAL BUREAU OF ECONOMIC RESEARCH \\ 1050 Massachusetts Avenue \\ Cambridge, MA 02138 \\ March 2018
}

We greatly benefited from the insights, comments, and suggestions of anonymous referees, Scott Ashworth, Ethan Bueno de Mesquita, Georgy Egorov, Anthony Fowler, Moritz Hennicke, Debraj Ray, Howard Rosenthal, Keith Schnakenberg, Konstantin Sonin, Thomas Stratmann, Francesco Trebbi, Richard Van Weelden, and seminar and conference participants at the Barcelona GSE Summer Forum, Harris School of Public Policy (U. Chicago), Harvard, University of Konstanz, LSE, University of Namur, NBER PE workshop, Ecole Polytechnique, Pompeu Fabra University, Royal Holloway, UBC, Wallis Institute, University of Utah, Princeton University, Duke University as well as from observations, in a previous step of this study, from audiences at Georgetown, Warwick, Mannheim, the Priorat Workshop in Theoretical Political Science, and EPSA. This project has received funding from the FNRS (Micael Castanheira) and the European Research Council (Laurent Bouton) under the European Union's Horizon 2020 research and innovation programme (grant agreement No 637662). Drazen gratefully acknowledges research support from the National Science Foundation, grant SES 1534132. The views expressed herein are those of the authors and do not necessarily reflect the views of the National Bureau of Economic Research.

NBER working papers are circulated for discussion and comment purposes. They have not been peer-reviewed or been subject to the review by the NBER Board of Directors that accompanies official NBER publications.

(C) 2018 by Laurent Bouton, Micael Castanheira, and Allan Drazen. All rights reserved. Short sections of text, not to exceed two paragraphs, may be quoted without explicit permission provided that full credit, including $\odot$ notice, is given to the source. 
A Theory of Small Campaign Contributions

Laurent Bouton, Micael Castanheira, and Allan Drazen

NBER Working Paper No. 24413

March 2018

JEL No. D72

\section{ABSTRACT}

We propose a theory of small campaign contributions driven by an electoral motive, i.e., the desire to influence election outcomes. Though small donors take as given the actions of others, strategic interactions induce patterns consistent with empirical findings, e.g., election closeness and underdog effects. We also study different forms of campaign finance laws, and show why caps should be combined with a progressive tax on contributions. Next, we introduce large donors and show that several conclusions in the literature may be significantly modified by the interaction with small donors. Throughout, we discuss the empirical implications of our findings.

Laurent Bouton

Georgetown University

Department of Economics

37th \& O Streets, NW

Washington,DC 20057

and CEPR

and also NBER

boutonllj@gmail.com

Micael Castanheira

ECARES, ULB CP 114

50 Av. F.D. Roosevelt

1050 Brussels, Belgium

micael.casta@gmail.com
Allan Drazen

Department of Economics

University of Maryland

College Park, MD 20742

and NBER

drazen@econ.umd.edu 
An informed public of small contributors "would make the millions feel that it was their government, as it is; and that you and your administration were beholden to the many, not to the few." — Lincoln Steffens to Theodore Roosevelt, September 21, 1905

(Doris Kearns Goodwin, The Bully Pulpit, p. 417)

\section{Introduction}

The role of campaign contributions in elections is a central issue in democracies. Yet both popular and academic discussions have mostly concentrated on large donors, despite the fact that small donors account for a large fraction of total contributions. In the 2012 U.S. presidential campaign for instance, the Federal Election Commission reported that out of a total campaign spending of about $\$ 1.3$ billion for the main candidates, small contributions (less than $\$ 200$ each) added up to $\$ 621$ million, and those between $\$ 200$ and $\$ 1000$ to another $\$ 243$ million. ${ }^{1}$ The numbers tilted even further towards small contributions in the 2016 presidential race: Bernie Sanders, for example, raised 202 million dollars from small contributions, out of a total campaign budget of 223 million, while Hillary Clinton and Donald Trump also each received more than 2 million from small donors.

Small donors are important in other countries as well. In Canada, they represent about a third of total funds raised for recent campaigns. This figure is similar in the United Kingdom, where a significant share of party funding comes from membership dues and small donations (the Labour party, for example, reported £19.2 million in donations and $£ 9.5$ million in membership dues in 2015). ${ }^{2}$ In Germany, they likewise represented about $53 \%$ of campaign resources in the 2012 cycle, about half that amount reflecting party membership dues. ${ }^{3}$ Small contributions account for such a significant fraction of total funding due to the considerable number of small donors.

To the best of our knowledge, there is no formal model of small campaign contributions in the literature. Thus far, the focus has been on large donors with a policy influence motive for contributing. ${ }^{4}$ For small donors, a consumption motive is put forward almost

\footnotetext{
${ }^{1}$ http://www.fec.gov/disclosurep/pnational.do;jsessionid=5E34A548A5EEB1D08BBECEA07049DF53.worker1 and http://www.fec.gov/disclosurep/pnational.do

${ }^{2}$ http://search.electoralcommission.org.uk/Api/Accounts/Documents/17488

${ }^{3}$ Most of the rest being public funding, while medium and large contributions represented about $9 \%$ of the total.

${ }^{4}$ The leading theoretical model is that of Grossman and Helpman (1994, 1996), although the empirical literature finds mixed support for an influence motive (Stratmann, 1992; Ansolabehere, de Figueiredo and Snyder, 2003; Gordon, Hafer, and Landa 2007; Chamon and Kaplan 2013, DellaVigna et al. 2016, Avis 2018). Hence, it is not clear to what extent large contributions "buy" policy favors.
} 
by default. ${ }^{5}$ The basic reasoning is that when individual contributions are small, donors cannot be motivated either by an attempt to "buy" influence or by any effect their contributions may have on election outcomes (an electoral motive).

Yet, as we discuss at length in the next section, there are compelling reasons why an electoral motive for small donors deserves closer attention. Moreover, developing a model of electorally-motivated contributions allows us to generate predictions that can then be tested against patterns of contributions observed in real life. Indeed, we find strong support for our results in the empirical literature.

In this paper, we thus propose a theory of small campaign contributions motivated by the desire of either donors (Section 3 ) or candidates (Section 5) to influence election outcomes. By "small," we mean that a donor takes as given both the policy of candidates (i.e., there is no motive of trading contributions for policy favors) and the behavior of other donors. ${ }^{6}$ However, electoral considerations necessarily produce strategic interactions: total contributions determine the influence of money on outcomes, and hence individual best responses. As a result, the comparative statics on individual and total contributions are quite different than those implied by theories that ignore such interactions (e.g., a basic theory of contributions driven solely by the pure consumption motive). These differences can help explain a number of empirical observations that seem anomalous when contributions are viewed either as consumption or as an attempt to buy influence.

We begin by developing a simple theory of small contributions with a model of small donors only. After laying out the small-donors model of a two-candidate race in Section 3.1, we characterize the equilibrium in Section 3.2. Importantly, we show that equilibrium contributions increase when the support for the two candidates is more even, that is, a "closeness effect," and that relative contributions for the advantaged party are smaller than their underlying advantage, that is, an "underdog effect." Although this result is in line with a number of empirical findings on individual contributions, it contrasts with the predictions under both the influence motive and the consumption motive; the former would lead to a "bandwagon effect" in contributions, the latter would imply no such effects.

\footnotetext{
${ }^{5}$ Ansolabehere et al. (2003) have stressed this view, arguing that the "tiny size of the average contribution made by private citizens suggests that little private benefit could be bought with such donations" (p117). They support their claim with the finding that "income is by far the strongest predictor of giving to political campaigns and organizations, and it is also the main predictor of contributing to nonreligious charities" like other normal consumption goods.

${ }^{6}$ Hence, "small" may also characterize donations above any specific amount, such as $\$ 200$, if these criteria are satisfied.
} 
In addition, we study the effects of income and income inequality on the contributions to the two candidates. As with a consumption motive, donations are predicted to increase in income (as well as the ideological proximity between candidates and donors). However, strategic interactions also imply that income inequality has significantly different effects if income inequality affects the supporters of the leading instead of the trailing candidate.

In Section 3.3, we analyze the effects of various campaign finance laws on the behavior of small donors. We find that a cap on individual contributions affects all donors, including those not directly hit by the cap. The cap generally favors the candidate with the largest number of donors and works against the one with the richest donors, but these effects are not necessarily monotonic. Furthermore, we examine the effects of public subsidy and taxation schemes. We find that matching subsidies have limited or no effects, and that it is possible to eliminate the effects of income inequalities on campaign contributions by implementing a progressive tax on contributions.

We then study the interactions between small and large donors by embedding the smalldonors model into a dynamic game in which large donors have a first-mover advantage. We consider the problem of a large donor who supports one of the candidates. She contributes to a candidate at an early stage of the campaign, when candidate platforms are potentially still fluid, and before small donors make their decisions (see discussion in Section 4). Thus, when deciding how much to contribute, the large donor takes into account the effect of her contribution on the behavior of small donors in the next phase of the campaign. In line with the findings in the literature, we allow for the donor to be motivated both by a desire to curry favors (influence motive) and by a desire to influence the outcome of the election (electoral motive).

The results of the small-donor-only model extend to the generalized model, but also provide additional insights on the interactions between small and large donors. To this regard, we document four novel findings. First, we identify a new indirect cost of contributing that arises specifically from the interactions with small donors. This induces large donors to moderate their contributions, and their request for favors. Second, we find that the importance of the two motives underlying large donors' contributions moves in opposite directions with the closeness of the election. As a consequence, our model predicts that policy favors should be more prevalent in lopsided elections. Third, we find that capping small contributions during the electoral campaign, while not effectively capping large donors (e.g., because they can make their contributions through other, uncapped 
conduits such as super PACs) has highly perverse effects. Such a cap, even if it barely affects their contribution levels, limits the small donors' room for manoeuvre, effectively reducing the indirect cost. This boosts large donors' requests and favors extraction. Finally, capping contributions by large donors can end up boosting the electoral prospects of the candidate most hit by the cap (due to the composition of his support among donors). This again results from the interactions with small donors.

At various places throughout the paper, we show how our findings may inform empirical research. First, the different motives for contributions produce qualitatively different donor responses, which could be leveraged to further understanding of small donors' motivations (see, e.g., Ansolabehere et al. 2003 and Barber et al. 2017). Second, our results also show how estimates of the income elasticity of contributions (see, e.g., Gordon et al. 2007, and Bonica and Rosenthal 2018) may be influenced by aggregate, equilibrium, responses. We also find that the direction of some effects crucially depends on whether the candidate is ahead or behind, as well as on the specifics of the income shock. Third, estimates of the effects of changes in campaign finance laws (such as caps on individual contributions) on electoral outcomes (see, e.g., Lott 2006, and Stratmann and Aparicio-Castillo 2006) are also subtle. Our model predicts that such effects are non-monotonic and may change sign depending on the source of the difference in popularity between candidates. Finally, caps that only bind for some specific donors may also substantially affect the behavior of other, uncapped, donors.

\section{On the Electoral Motive}

Starting with Ansolabehere et al. (2003), significant empirical effort has been invested in assessing the motives behind contributions, either those of individual donors or corporations (see, e.g., Bertrand et al. 2014 and DellaVigna et al. 2016). For small donations, it has generally been argued that each contribution is far too small relative to the total to have any effect in influencing either policy choices or election outcomes. Given the "almost zero" effect small donations are perceived to have, a consumption motive has thus been put forward. An electoral motive has been largely omitted from these analyses, basically by default, rather than due to empirical evidence of its absence.

We argue in this paper that the electoral motive should not, however, be dismissed out of hand. In fact, there is substantial empirical evidence supporting the electoral motive. 
First, in surveys, donors overwhelmingly list "to affect an election outcome" as an important motive for giving (Brown et al. 1995; Francia et al. 2003; Barber 2016a). Second, numerous studies find ideological proximity to be a strong determinant of contributor behavior in different types of contests (see, e.g., McCarty, Poole, and Rosenthal 2006; Claasen 2007; Bonica 2014; Barber 2016a; Barber, Canes-Wrone, and Thrower 2017). We will see that the distance between the ideological positions of donors and candidates does also matter for donors who care only about election outcomes. ${ }^{7}$ Last but not least, as discussed extensively in Section 3.2, three key predictions of our "rational-instrumental" donor model are in line with empirical patterns in the literature: (i) closeness effect: donations are significantly and positively affected by the (perceived) closeness of the election; (ii) underdog effect: relative contributions to the front-runner are always smaller than her intrinsic advantage; (iii) income effect: donations are increasing in the wealth of donors. While one cannot reject that these patterns may be consistent with another theory of small campaign contributions, they show that electoral considerations must be part of that theory. This is exactly what we do in Section 5, where we develop a demand-driven model of small contributions that delivers the exact same predictions (more details below).

Why would electoral considerations be so important given the almost zero effect of individual small donations on the electoral outcome? There is of course a distinction between the comparative static effects we identify and the magnitude of these effects. Electoral considerations, and hence the qualitative predictions of our model, are identical whether we view donors as fully rational or as behavioral. In contrast, quantitative implications are highly sensitive to the details of the utility and/or cost functions. We argue that electorally-motivated behavioral factors may well yield significantly larger empirical effects. For example, donors may overestimate the effect of their contributions on the electoral outcome by orders of magnitude, which would be in line with the results of surveys about donors' motivation.

Another possible explanation is that the electoral motive operates through the fundraising behavior of candidates. In Section 5, we formally show the equivalence between the model developed in the core of the paper and a model in which "naive" donors respond to their candidate's fund-raising effort. The relevant assumption is that candidates believe that money is crucial to winning an election. This certainly seems to be the case: as Jesse

\footnotetext{
${ }^{7}$ A related observation from Barber et al. (2017, p.283) is that contributions are made to legislators who "will represent their professional interests, rather than due to expectations of legislative access or an unsophisticated response to networking." This too is consistent with an electoral motive rather than simply a consumption motive for giving.
} 
Unruh said when he was Speaker of the California State Assembly in 1966, "Money is the mothers' milk of politics," a view clearly supported by the enormous effort candidates put into fund-raising. Voters respond to such efforts: Magleby et al. (2018), for example, document large spikes in donations on days that candidates increase their fund-raising effort. (More generally, these are known as "moneybomb" events, a highly lucrative grassroots fund-raising effort over a brief period. $)^{8}$

A remaining important issue is whether money actually matters for electoral outcomes. The empirical literature can be divided into two sets of studies. The first focuses on the effect of specific campaign spending (e.g., TV ads) with recent studies, with well-defined identification strategies, finding positive and significant effects (see, e.g., Da Silveira and De Mello 2011; Kendall et al. 2015; Larreguy et al. 2018; Spenkuch and Toniatti 2018; and Bekkouche and Cage 2020). The second analyzes the effects of total spending. Here, however, the evidence is mixed: spending by challengers appears more effective than spending by incumbents and, for the latter, no consensus has been reached as to whether the effect of money is economically significant (see, e.g., Levitt 1994; Erikson and Palfrey 1998, 2000; Gerber 2004; Benoit and Marsh 2008; Stratmann 2009; Bombardini and Trebbi 2011; and Kawai and Sunada 2015). A simple way to reconcile the apparent contradiction between these two sets of studies is provided by Sprick Schuster (2020). Using detailed transaction-level data on candidate disbursements, he finds systematic differences in the way incumbents and challengers allocate their campaign resources. In particular, incumbents spend a smaller share of their total spending than challengers on "messages to voters" (i.e., advertising and events), and a larger share on other types of spending, such as refunding of contributions and donations to other campaigns. These latter types of spending have arguably no effect on their chances of winning their own race.

\section{Small Donors}

We begin by setting out our theory of electorally-motivated small contributions. Hence, this section considers a simple model with small donors only. In Section 4, we embed this model of small donors model into a dynamic game in which a large donor has first mover advantage. We will see that the results of the simple model extend to the generalized

\footnotetext{
${ }^{8}$ Note however that such a demand-driven model does not seem to fully capture the small contributions phenomenon. Magleby et al. (2018, p. 357) find that "A third of those [small donors] who donated in 2008 reported they gave without being asked to do so, 37 percent for Obama, and 25 percent for McCain."
} 
model, although with additional and novel insights on the interactions between small and large donors.

\subsection{The Model}

There are two candidates, $A$ and $B$, who need funding to finance their electoral campaigns. Our key assumption is that money affects the outcome of the election (see discussion at the end of Section 2). We summarize this through a contest success function. ${ }^{9}$ This captures the idea that these funds are used to finance activities such as get-out-the-vote efforts (see Enos and Fowler, 2016) or advertising (as for example in Baron, 1994, Prat, 2002, Coate 2004a,b, and Morton and Myerson, 2012), which may increase a candidate's vote totals. As Cmar (2005) put it, "a political campaign is almost never successful unless its resources are comparable to those of its opponents - and the most important of these resources is money."

Formally, given total contributions $\mathbf{S}=\left\{S_{A}, S_{B}\right\} \in \mathbb{R}_{+}^{2}$ by small donors, A's probability of winning the election is given by:

$$
\pi_{A}(\mathbf{S})=\frac{S_{A}}{S_{A}+S_{B}}=\frac{1}{1+\left(\frac{S_{B}}{S_{A}}\right)}, \text { with } 0<\leq 2,
$$

for $\max \left\{S_{A}, S_{B}\right\}>0$, and $\pi_{A}(\mathbf{S})=x \in[0,1]$ for $S_{A}=S_{B}=0$ (see Esteban and Ray, 1999). Note that $\pi_{P}$ is everywhere concave in $S_{P}$ for $\leq 1$. Values of $>1$ capture the presence of setup costs: $\pi_{P}$ is then convex for $S_{P}<\bar{S}_{P} \equiv \sqrt{\frac{\square 1}{+1}} Q_{\square P}$. In words, $P^{\prime}$ 's campaign must reach $\bar{S}_{P}$ for additional contributions to have maximal effect. Figure 2 illustrates the shape of $\pi_{A}$ for $=1$ (dotted line), $=2$ (dashed), and $=3$ (solid) when $S_{B}=1$.

Small donors simultaneously and non-cooperatively select which amount $s_{P}^{i}$ to contribute to their preferred candidate, with $\sum_{i} s_{P}^{i}=S_{P} .{ }^{10}$ Each small donor $i$ has a twodimensional type $p^{i}, y^{i}$ ), where $p^{i} \in\{A, B\}$ identifies who is his preferred candidate/party and $y^{i}$ represents $i$ 's income (which will influence his willingness to contribute.) There are $n_{P}$ donors of type $P$, distributed in income classes $y^{1}<\ldots<y^{G}$ according to some (dis-

\footnotetext{
${ }^{9}$ This is inspired by an increasingly large literature: see Tullock (1980), Hirshleifer (1989), Baron (1994), Skaperdas and Grofman (1995), Esteban and Ray (2001), Epstein and Nitzan (2006), Konrad (2007), Jia et al. (2013), Herrera et al. (2014, 2016), among others.

${ }^{10}$ A similar setup with many individual players investing resources to collectively fight over an issue has been pioneered by Katz et al. (1990) for rent-seeking, and by Esteban and Ray (1999, 2001) for conflict situations.
} 


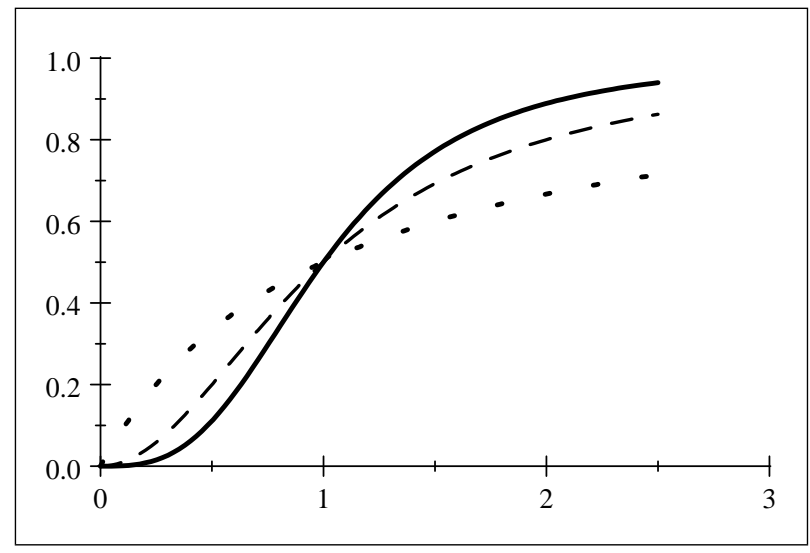

Figure 1: $\pi_{A}\left(S_{A}, S_{B}\right)$ for $S_{B}=1$ and $=1($ dot $), \quad=2($ dash $)$, or $=3$ (solid)

crete) cumulative distribution function $F_{P} y^{i}$ ) with $F_{P}(0)=0$, and $\left.F_{P} y^{G}\right)=1$. The fraction of type- $P$ donors with income $y^{i}$ is denoted $\left.\left.\left.f_{P} \quad y^{i}\right)=F_{P} \quad y^{i}\right) \square F_{P} \quad y^{i \square 1}\right) \geq 0$.

Given our focus on the electoral motive, we consider small donors who contribute to influence the election outcome. Each small donor contributes some amount $s_{P}^{i} \in(0, \bar{s}]$, where $\bar{s}$ is the legal contribution limit. We thus concentrate on the intensive margin. ${ }^{11}$ Letting the costs of contributions being increasing and convex, i.e. $\rho>1$ (we will focus on the case $\rho=2$ in most of the paper), the objective function of a small donor is:

$$
\max _{s_{P}^{i}} \pi_{P}(\mathbf{S}) v_{P} \square \frac{\left.\square_{P}^{i}\right)^{\rho} / \rho}{\left(y^{i}\right)^{\theta}},
$$

where $v_{P}$ is the utility that a small contributor attaches to his candidate $P$ being elected. The parameter $\theta$ will determine the elasticity of contributions with respect to income: for $\theta=0$, the cost of contributing is independent of income. For $\theta>0$, (total and marginal) costs are strictly decreasing in $y^{i}$.

\subsection{Equilibrium Analysis}

For now, we abstract from potential contribution caps and show that there exists only one candidate pure strategy Nash equilibrium of this contribution game, and we identify sufficient conditions for existence. We then show that total contributions (1) increase in

\footnotetext{
${ }^{11}$ Some donors could be at a corner solution, contributing exactly zero when they expect to have too low an effect on the election, and move to an interior solution when this effect increases in magnitude. In essence, this extensive margin is the focus of the turnout models discussed in Section 3.2. For the sake of simplicity, and since these effects are known, we abstract from them here.
} 
the closeness of the election, (2) display a partial underdog effect, and (3) increase with income and income inequalities. Formally, the first two observations mirror existing results on voter turnout. The novelty lies more in identifying how they match empirical patterns of contribution behavior, both in observational and experimental settings. The comparative statics about income and income inequalities are more novel from a theoretical standpoint. They also find support in the data.

As a first step on the way to solving for the equilibrium, we derive a small donor's best response given the other donors' contributions. To this end, we take first order conditions of the utility function (2) with respect to the individual donor's contribution, $s_{P}^{i}$ :

$$
\begin{array}{ll}
\text { For types } A: & \left.s_{A}^{i}=\frac{d \pi_{A}}{d S_{A}} y^{i}\right)^{\theta} v_{A} \\
\text { For types } B: & \left.s_{B}^{i}=\frac{d \pi_{B}}{d S_{B}} y^{i}\right)^{\theta} v_{B},
\end{array}
$$

where we have used the fact that $d S_{P} / d s_{P}^{i}=1$. The term $d \pi_{P} / d S_{P}$ embodies the electoral motive for small donors. Put simply, donors with an electoral motive contribute more when they perceive that their contribution has a higher impact on their candidate's probability of winning. (The other two elements in the best response function are discussed below)

Central to the electoral motive is the fact that it generates non-trivial strategic interactions: while each individual increases her contribution when $d \pi_{P} / d S_{P}$ increases, the combined responses of all donors also feed back into $d \pi_{P} / d S_{P}$. To evaluate these twoway interactions, we aggregate small donors' best responses into their total contribution. Adding up individual best responses and simplifying yields:

$$
\begin{aligned}
S_{P}= & \left.\sum_{i \in\left\{s_{P}\right\}} \frac{d \pi_{P}}{d S_{P}} y^{i}\right)^{\theta} v_{P}=\sqrt[p]{W_{P} \quad \pi_{A}\left(1 \square \pi_{A}\right)}, \\
& \text { where } \left.\left.W_{P} \equiv n_{P} v_{P} \sum_{i=1}^{G} f_{P}^{\square} y^{i}\right) \times y^{i}\right)^{\theta}=n_{P} v_{P} \bar{Y}_{P}
\end{aligned}
$$

We will interpret $W_{P}$ as the candidate's intrinsic support among small donors, reflecting their numbers $\left(n_{P}\right)$, intensity of preferences $\left(v_{P}\right)$, and distribution of income $\left(\bar{Y}_{P}\right)$. We label $A$ the candidate who is ahead and $B$ the candidate who is behind, in the sense that $W_{A} \geq W_{B}$.

Using this notation, we find that: 
Proposition 1 Whenever a pure strategy equilibrium exists, it is unique and characterized by the aggregate contributions:

$$
\left(S_{A}^{*}, S_{B}^{*}\right)=\left(\sqrt[\rho]{\omega W_{A}^{\rho \square 1}}, \sqrt[\rho]{\omega W_{B}^{\rho \square 1}}\right)
$$

with $\omega \equiv \frac{\left(W_{B} / W_{A}\right)^{\left(1 \square \frac{1}{\rho}\right)}}{\left(1+\left(W_{B} / W_{A}\right)^{\left(1 \square \frac{1}{\rho}\right)}\right)^{2}}$ representing the closeness of the election. ${ }^{12}$ The associated winning probabilities are:

$$
\pi_{P}^{*}=\frac{\left(W_{P}\right)^{\frac{\rho \square 1}{\rho}}}{\left(W_{A}\right)^{\frac{\rho \square 1}{\rho}}+\left(W_{B}\right)^{\frac{\rho \square 1}{\rho}}} .
$$

Two sufficient conditions for the existence of a pure strategy equilibrium are: (1) $\leq \rho$ and, if $>\rho$, (2) $W_{A} / W_{B}$ not too large.

The proof of the first part of the proposition is straightforward: it consists of substituting for $\pi_{P}^{\prime}$ in (5), and solving for the contributions that are consistent with best responses. The second part is about ensuring that second order conditions are satisfied. What we find is that the solution to the first problem is unique, but it is only an equilibrium when either (1) the problem does not display non-convexities or (2) the race is not too lopsided.

The equilibrium winning probabilities in (6) show that a candidate can only benefit from having higher intrinsic support $W_{P}$ among her donors. ${ }^{13}$ This can result from receiving contributions from more donors, from higher income donors and/or donors with more intense preferences. The effect on the size of the campaign $\left(S_{A}^{*}+S_{B}^{*}\right)$ and on individual contributions is however less than straightforward. We summarize them by studying three important implications of Proposition 1. In the remainder of the paper, we restrict our attention to the case $\rho=2$ for the ease of readability.

\subsubsection{Election Closeness}

The first corollary of Proposition 1 is that, when the electoral motive shapes contributions:

\footnotetext{
${ }^{12}$ Note that $\omega$ is a direct transformation of $\pi_{A}^{*}\left(1 \square \pi_{A}^{*}\right)$, but expressed in terms of the primitives of the model. It is increasing in $W_{B} / W_{A}, \forall W_{B} / W_{A}<1$, and decreasing in $W_{B} / W_{A}, \forall W_{B} / W_{A}>1$. It is thus maximized in $W_{B}=W_{A}$, or $\pi_{A}^{*}=1 / 2$.

${ }^{13}$ In a different context, Esteban and Ray (2001) show that this is partly due to the shape of the cost function, and partly to winning the election acting as a public good. We use the qualifier "partly" because they focus on the case in which $=1$. For that value of , Esteban and Ray (2001, Proposition 3) identify that free-riding effects cannot dominate collective action when payoffs are similar to that of a purely public good, as we have here.
} 
Corollary 1 Small donors' contributions $s_{P}^{i}$ increase in election closeness, as measured by $\left|\sqrt{W_{A} / W_{B}} \square 1\right|$ or $\left|\pi_{A}^{*} \square 1 / 2\right|$.

This is similar to formal results in the literature on voter turnout, which say that voters should be more likely to vote when they are more likely to affect the election outcome, i.e. when the election is close (see e.g. Palfrey and Rosenthal 1985, Castanheira 2003, Feddersen and Sandroni 2006, or Herrera et al. 2014, 2016). Corollary 1 shows formally how election closeness also influences contributions by small donors.

Empirically, this effect of (perceived) election closeness appears quantitatively important: combining survey data on US donors with FEC data, Barber et al. (2017, p.17) shows that "a standard deviation increase [in competitiveness] raises the likelihood a donor gives to that campaign by $43 \%$." Jacobson $(1980,1985)$ studies how the expected closeness of a US congressional election, proxied by the winner's share of the two-party vote in the last election, affected campaign contributions between 1972 and 1982. In line with Corollary 1 , he finds that the closer the race, the larger are contributions to both the challenger and the incumbent. Culberson et al. (2019) focuses on small contributions and finds similar results for US House elections between 2006 and 2010. To control for hidden heterogeneity, Mutz (1995) and Fuchs et al. (2000) study the dynamics of a given campaign to see how shocks to perceived closeness and other events influencing the marginal effect of contributions affect donor behavior. They consistently find that, when the race between the front-runner and the runner-up narrows, contributions to both candidates increase.

\subsubsection{Underdog Effect}

A second implication of Proposition 1 is that equilibrium contributions are affected by free riding. The fact that $A$ is ahead implies that the problem is more salient among $A$-donors:

Corollary 2 In any equilibrium, the ratio of small contributions for $A$ and $B$ displays an underdog effect:

$$
\frac{S_{A}^{*}}{S_{B}^{*}}=\sqrt{\frac{W_{A}}{W_{B}}} \quad\left(<\frac{W_{A}}{W_{B}}\right) .
$$

That is, relative contributions for $A$ by small donors are always smaller than $A$ 's intrinsic advantage among small donors.

This underdog effect results from individual free riding among small donors: since $A$ is ahead among small donors, each $A$-donor will tend to contribute less ceteris paribus than 
a $B$-donor. ${ }^{14}$

The underdog effect has also been identified in theoretical models of turnout (see e.g. Palfrey and Rosenthal 1985, Castanheira 2003, Feddersen and Sandroni 2006 and, for models that use the contest success function, Herrera et al. 2014, 2016, and Kartal 2015). ${ }^{15}$ We are not aware of a similar finding regarding political contributions; to the contrary, the main rationale for strategic contribution is the policy influence which would predict a bandwagon effect (comparatively more contributions to the advantaged candidate) while the "pure" consumption effect would predict no effect. As explained by Mutz (1995, p1019), "[i]n fact, many studies of bandwagon phenomena have ended up demonstrating strong underdog patterns rather than movement in the direction of majority opinion."

The most direct piece of evidence of an underdog effect comes from the field experiment reported in Rogers and Moore (2014) and Rogers, Moore, and Norton (2017, pp. 12981300). They contacted more than 660,000 people on the fund-raising list of the Democratic Governors Association and invited contributions to the campaign of Charlie Crist, the Democratic candidate for governor in Florida in 2014. They divided the sample in two, and sent two variants of an otherwise identical e-mail: one depicted the candidate as leading in the polls, the other one as trailing behind. Their overall result is that people are more motivated to support the candidate when he is presented as losing in the polls. In particular "the losing message increased the number of donations among past donors by $33 \%$ and raised $76 \%$ more money" (Rogers and Moore 2014, p16) and "controlling for donor status, [recipients of the winning message] gave less money than [recipients of the losing message]" (Rogers et al. 2017, p1299).

Another type of evidence comes from the analysis of candidate fund-raising strategies. As explained by Mutz (1995, p1019): "Outside the context of direct-mail fund-raising, it is also common for candidates to vie for the 'underdog' role for similar reasons (see Adams 1983). [...] In the face of an imminent threat, [supporters] may be prompted to give money by news that their candidate is threatened or losing ground." Rogers and Moore (2014) report similar findings in both the Obama and Romney campaigns: "when the campaign messages communicate that the race is close, the majority of those messages assert that the candidate is losing" (p24).

\footnotetext{
${ }^{14}$ This is because the marginal return of contributing should be lower for the leading candidate, which is actually the exact finding of Erikson and Palfrey (2000). They find that the effect of contributions on the election outcome is larger for the trailing candidate unless the race is close.

${ }^{15}$ In voting models, the underdog effect results from pivot probabilities being higher for the underdog (see among others Castanheira (2003), Myatt (2015), Agranov et al. (2014)).
} 
This is not to say that there is no evidence of any bandwagon effect for other types of donors, PACs in particular (see e.g. Stratmann 1992), or for multicandidate races in which some candidates' viability may be in doubt. In primaries for instance, most donors want to focus on the top two or three candidates (Hall and Snyder 2014). This temporarily creates significant bandwagon effects when the names mentioned for the top two or three change over the course of the campaign, while the underdog effect remains dominant for the frontrunner (Mutz 1995, Fuchs et al. 2000, Feigenbaum and Shelton 2013). ${ }^{16}$

Finally, Bonica (2016, Figure 2) compares the behavior of small donors from other donor types, in particular from Corporate PACs. Small individual contributions disproportionately flow to underdogs: depending on the election cycle, only 48 to $55 \%$ of their funds go to the winner, instead of $80-90 \%$ for Corporate PACs, to be compared to an average vote share of 60 to $65 \%$ - which could be used as a rough proxy for $W_{A} /\left(W_{A}+W_{B}\right){ }^{17}$

\subsubsection{Income and Income Inequality}

The literature typically approaches the issue of income and contributions from a different angle: the focus is on how income skews policies towards the rich and unduly favors the party with the richest supporters (see e.g. Coate 2004a,b, and Feddersen and Gul 2015). In this section, we instead focus on how income inequality influences campaign contributions by small donors when platforms have already been chosen - the case of large, early donors influencing platforms, with consequences on small donors' contributions, is analyzed in Section 4 .

Central to our analysis is the result that the income elasticity of contribution is positive and equal to $\theta$ (see (3) and (4)). The prediction immediately follows from the fact that the marginal cost of contributions is lower for donors with higher income. There is a lot of evidence that political participation in general, and campaign contributions in particular, is heavily tilted towards high-income citizens (see e.g. Schlozman, Verba and Brady 1995, 2012, Bonica et al. 2013, Malbin 2013). Gordon et al. (2007) also report positive income elasticities for the individual contributions of executives - note that, in the absence of

\footnotetext{
${ }^{16}$ In a companion paper (Bouton et al. 2018), we analyze elections with more than two candidates, and find that the electoral motive produces a bandwagon effect for longshot candidates (these are abandoned by instrumental donors when perceived as having too low a chance of winning the election), and an underdog effect for the top-two candidates.

${ }^{17}$ Authors' computation based on Bonica's dataset (Bonica, Adam. 2016. Database on Ideology, Money in Politics, and Elections: Public version 2.0. Stanford, CA: Stanford University Libraries. $<$ https://data.stanford.edu/dime $>$ ). We thank Moritz Hennicke for his thorough work on these data.
} 
strategic interactions, their estimate would be a direct measure of $\theta$ in our model; this would be as high as 5 according to their main estimation (Table 1). Bonica and Rosenthal (2018) instead obtain wealth elasticities "quite close to zero" for democrats, and slightly below 1 for republicans. Although their interpretation is different, Ansolabehere et al. (2003, p122) find an income elasticity slightly above one, and income growth explains about $80 \%$ of the observed increase in contributions.

Arguably, all these empirical findings depict $(i)$ equilibrium behavior, with the proviso that free-riding effects may bias estimates of $\theta$ downward; (ii) of very wealthy individuals, due to lack of data on smaller donors. Yet, two remarks are in order: first, remember that the definition of a "small donor" in the model has more to do with timing-small donors move too late to influence either other donors or the candidates' platforms-than with income. Second, as we will see in Section 4, our model predicts similar income effects for large donors who move early in the campaign, independently of their motive.

Another finding is that income inequality tends to stimulate total contributions, with a spillover effect on the other group of donors:

Proposition 2 If and only if the income elasticity of contributions is larger than 1, a mean-preserving spread:

(1) of the A-donors' income distribution increases $S_{A}^{*}$ and decreases $S_{B}^{*}$.

(2) of the B-donors' income distribution increases both $S_{A}^{*}$ and $S_{B}^{*}$.

We need two elements to clarify the intuition behind this result. The first is the connection between a mean-preserving spread and the income elasticity of contributions. If and only if $\theta$ is strictly larger than 1 , contributions become a convex function of individual income. Increasing within-group inequality then increases intrinsic support $W_{P}$. The second is the spillover channels across groups: Lemma 1 in the appendix shows that a same increase in $W_{P}$ has opposite spillover effects depending on whether $P$ is $A$ head or $B$ ehind. The logic is as above: from Corollary 1 , the reaction of donors for the other candidate will depend on whether the election becomes closer or more lopsided.

Combining these two elements produces the proposition: increasing inequality within the group of $A$-donors increases their willingness to pay, and therefore $A$ 's lead. This in turn depresses contributions by $B$-donors. A same increase among $B$-donors instead makes the election closer, which increases contributions by $A$-donors. The same mechanisms can be applied to changes in between-group inequality. 
To the best of our knowledge, there is no empirical work on the reactions of small donors to income inequality. Our results indicate that, because "income inequality" is not a sufficient statistic to identify the direction of all these effects, empirical work may benefit from carefully distinguishing between the different shocks to the overall income distribution.

\subsection{Campaign Finance Laws: Effects on Small Donors}

Campaign finance laws are, generally speaking, meant to limit the influence of money in politics (see, e.g., Ashworth 2006, Coate 2004a,b). One rationale is that contributions buy policy influence outside of any direct effect on voting, that is, trading contributions for policy favors in a "quid pro quo" (see section 4). Such a rationale, as important as it might be for large and early contributions, plays essentially no role for small contributions. ${ }^{18}$

A second rationale to limit campaign spending is that it is like an "arms race" - what is crucial in the end is the level of total contributions relative to those of one's opponent. Hence, the level of money ratchets up without giving either candidate a relative advantage but draining resources nonetheless. Our small donor model captures well that feature of campaign spending. ${ }^{19}$

A third argument is that a donor's influence on elections is determined by the size of her contribution, so that larger contributions have undue effect on electoral outcomes. In that context, contribution caps are meant to ensure that the "voices of small donors" are also heard-this is sometimes referred to as the "equalization" argument. ${ }^{20}$ This is central to our paper, and we show here that this can happen even in the absence of the quid pro

\footnotetext{
${ }^{18}$ Coate (2004a) considers such negative welfare effects of contributions because they buy policymaker influence. In his setup, contribution limits may increase social welfare not only because they reduce such influence, but also - and because of this - such limits increase the information value of activities that contributions finance.

${ }^{19}$ Another important factor is incumbency, which typically provides a substantial exogenous advantage, that a challenger may find easier to overcome with money. See e.g. Lott (2006) and Bonneau and Cann (2011).

${ }^{20}$ The debate about campaign finance in the United States, as reflected in U.S. Supreme Court decisions, has been largely framed in terms of issues of 'freedom of speech'. In the famous Buckley v. Valeo decision, a majority held that limits on campaign spending and individual contributions in the Federal Election Campaign Act of 1971 were unconstitutional because they violated the First Amendment provision on freedom of speech, the argument being that a restriction on spending "necessarily reduces the quantity of expression". Arguments in favor of restrictions have also relied on such considerations. In Austin v. Michigan Chamber of Commerce (1990) the court had upheld previous limits on corporate spending, writing "Corporate wealth can unfairly influence elections." Analogously, Justice Stevens, in the minority dissent in Citizens United, reiterated the "unfair influence" argument, writing that "unregulated expenditures will give corporations 'unfair influence' in the electoral process and distort public debate in ways that undermine rather than advance the interests of listeners."
} 
quo component that we analyze in Section 4.1.

The main take away of our analysis is that, due to the strategic interactions highlighted in Section 3.2, campaign finance laws can have unintended consequences. Among other things, small donors will be affected even if they are not capped directly. To the best of our knowledge, such indirect effects have been ignored in the literature. Further, we identify when aggregate effects go the opposite direction of the direct effect of the cap.

\subsubsection{Caps on Individual Contributions}

The diversity of possible effects is illustrated in the following two propositions: the effects of contribution caps can go in exactly opposite directions, depending on whether the advantage of $A$ results from a larger number of donors (Proposition 3) or from wealthier donors (Proposition 4). Moreover, the effects need not be monotonic:

Proposition 3 Consider the case of identical income distributions and preference intensity $\left(v_{P}\right)$ for $A$ - and $B$-donors, but $n_{A}>n_{B}$. In that case:

(1) $\pi_{A}$ will be lowest when the cap is not binding;

(2) $\pi_{A}$ will be highest when the cap constrains all donors;

(3) Depending on the shape of the income distribution, the effects of varying the cap can be non-monotonic.

The main driver of the difference between (1) and (2) is the underdog effect (Corollary $2)$. With $n_{A}>n_{B}$, free riding implies that an $A$-donor with income $y^{i}$ contributes less than a $B$-donor with the same income. A binding cap must therefore constrain $B$-donors more than $A$-donors. Candidate $A$ is thus better off with a cap than with no cap, and best off when the cap is binding for all donors.

However, this still does not imply that the effects of a cap are monotonic, as illustrated in Figure 2. ${ }^{21}$ Indeed, capping high-income donors stimulates contributions by low-income donors and impacts closeness - remember that closer elections stimulate contributions in all groups. Thus, while the direct effect of the cap favors $A$ ( $B$-donors being more constrained), indirect effects tend to work in the opposite direction, and may dominate.

\footnotetext{
${ }^{21}$ The simulation behind Figure 2 builds on a two-group income distribution with $y_{l}=3$ and $y_{h}=10$; while we set $=\rho=2$, and $v_{P}=\theta=1$. The number of low- and high-income donors are: $n_{A, l}=60>$ $n_{B, l}=30$ and $n_{A, h}=20>n_{B, h}=10$. That is, both income classes are willing to contribute about the same amount (this proxies actual values in the 2015-16 US presidential elections), but there are twice as many $A$ - as $B$-donors, implying that $W_{A}=380$ and $W_{B}=190$.
} 


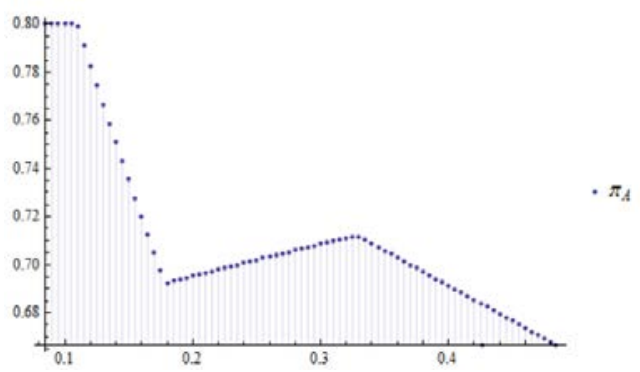

Figure 2: Simulated effect of an individual contribution cap (horizontal axis) on the probability of $A$ winning the election (vertical axis) when $n_{A}>n_{B}$ but the income distribution is identical across donor groups.

As figure 2 indicates, indirect equilibrium effects dominate for intermediate caps. In the example, this is due to the fact that small and comparatively large contributions both represent a significant fraction of the total (initially 50\%), with no intermediate contributions. This proxies what we typically observe in actual data, where there is a huge number of very small contributions, and another mass at higher levels (typically bunched at legal limits). Technically, when we move from lax to tighter caps, i.e. from right to left in the figure, the cap initially binds for high-income donors only, which corrects for the underdog effect among large contributions, but also increases the weight of small contributions in the total. When the cap is intermediate (caps between 0.18 and 0.33 in the figure) the underdog effect has been fully addressed among high-income donors, but has been reinforced among low-income donors. Since the latter represent an increasing fraction of the total, tighter caps now handicap $A$. In contrast, both lax (above 0.33) and tight (below 0.18 ) caps primarily reduce the underdog effect, which benefits $A$.

Now, contrast these results with the case in which the advantage of $A$ is due to higher donor income, rather than a numerically larger donor base:

Proposition 4 Consider the case in which $A$ and $B$ have equal popular support $\left(n_{A}=n_{B}\right)$ and preference intensity, but A-donors benefit from higher income, by a factor $k>1$ $\left.\left.\left(f_{A} k y^{i}\right)=f_{B} y^{i}\right), i=1, \ldots, G\right)$. In that case, the effects of a cap are the opposite of the ones in Proposition 3:

(1) $\pi_{A}$ will be highest when the cap is not binding;

(2) $\pi_{A}$ will be lowest when the cap constrains all donors;

(3) Depending on the income distribution, the effects can be non-monotonic. 
The intuition and the mechanism of the proof are similar to those of the previous proposition, with the difference that, if $A$-donors are richer but no more numerous than $B$-donors, they must be the first constrained. ${ }^{22}$ Hence, there are more type- $A$ than type- $B$ constrained donors, and any unconstrained $A$-donor contributes more than the equivalent $B$-donor. The logic is the same as above, although closeness and free-riding effects now work in the opposite direction: for high levels of the cap, i.e. $\bar{s} \in[0.51,0.7]$, the cap only binds $A$ high-income donors. This reduces the gap between contributions by $A$ and $B$ high-income donors. The slope reversal for $\bar{s} \in[0.25,0.51]$ happens when both $A$ and $B$ high-income donors are constrained: the only effect left is the equilibrium response of low-income donors, who weigh increasingly more in the total. Here, a marginal tightening of the cap favors $A$ because low-income $A$-donors are richer. The local maximum at 0.25 is reached when low-income $A$-donors start being capped, and the global minimum for $\bar{s} \in(0,0.22]$ is reached when all donors are capped. Then, the income differences that favored $A$ no longer define contributions.



Figure 3: Simulated effect of an individual contribution cap (horizontal axis) on the probability of $A$ winning the election (vertical axis) when $y_{A}^{i}=2 y_{B}^{i}$ but the number of donors is identical across donor groups.

The empirical literature on the effects of caps on individual contributions finds seemingly contradictory evidence. Stratmann and Aparicio-Castillo (2006) find that, for elections to US state Assemblies (lower house of a bicameral legislature) between 1980 and 2001, caps on individual contributions led to closer elections. ${ }^{23}$ Lott (2006) finds the op-

\footnotetext{
${ }^{22}$ This numerical example also builds on two income classes in each donor group: $y_{A, l}=6$ and $y_{A, h}=20$, $y_{B, l}=3$ and $y_{B, h}=10 ; \quad=\rho=2$, and $\theta=1$. Thus $A$-donors have twice the income of $B$ 's, while their numbers are identical: $n_{P, l}=30$ and $n_{P, h}=10, \forall P$. Hence, as in the previous example, $W_{A}=380$ and $W_{B}=190$.

${ }^{23}$ They also find that both the share and the absolute level of total contributions going to the incumbent decrease significantly. This is also in line with the result in Proposition 4. Stratmann (2006) find that, for the same elections, campaign spending by candidates (both incumbents and challengers) are more effective, and converge one towards the other, in elections with campaign contribution limits. This is also in line
} 
posite result for elections to US state Senates (upper house) from 1984 to 2002: caps led to more lopsided elections. ${ }^{24}$

Propositions 3 and 4 suggest avenues to reconcile these findings. First, empirical studies inevitably focus on the effects of "local" changes in caps on contributions. But, Propositions 3 and 4 show that such local effects need not be monotonic. Estimates as in Stratmann and Aparicio-Castillo (2006) and Lott (2006) may thus have opposite signs simply because the specific cap changes under study affect different parts of the distribution of donors. Second, these propositions also highlight how the effects of caps on individual contributions change sign depending on the main source of differences in support for the candidates. Our model thus suggests to explore in more details these sources for US state legislature elections. For instance, do we observe significant differences in the median number and value of individual donations for the candidates in those elections?

\subsubsection{Campaign Subsidies and Taxes}

Consider now the effects of campaign subsidies. We focus here on matching subsidies, where for each dollar of contributions, the government adds (or subtracts in the case of a tax on contributions) $m$ dollars. ${ }^{25,26}$ Total small contributions then become:

$$
\tilde{S}_{A}=\sum_{i=1}^{n_{A}}(1+m) s_{A}^{i} ; \text { and } \tilde{S}_{B}=\sum_{i=1}^{n_{B}}(1+m) s_{B}^{i} .
$$

We find that:

Proposition 5 A matching subsidy $m$ that applies to contributions by small donors has no effect on their behavior, nor on the outcome of the election.

The rationale behind this proposition is rather straightforward given winning probabilities follow a contest success function. Since the matching subsidy modifies each (and

with what our model predicts when the cap on contribution has a positive (or nill) effect on the closeness of the race. Indeed, the marginal effect of contributions increase when the total contributions to both parties go down (because of the free-riding effect), and their returns become more equal when $S_{A} \rightarrow S_{B}$.

${ }^{24}$ Similarly, Bonneau and Cann (2011) find that, in US state supreme court elections from 1990 to 2004 , campaign finance restrictions (more broadly defined) hurt challengers more than incumbents.

${ }^{25}$ Ashworth (2006) considers a situation that complements our analysis: in his model, incumbents may have an unfair advantage in fundraising, and matching subsidies are then a way to correct the situation. Yet, as he shows, welfare effects may be less than straightforward even in such a situation.

${ }^{26}$ In a previous version of the paper that omitted large donors, we also studied the effect of block subsidies, where the government gives a lump-sum to both candidates' campaigns. We found that these may increase or decrease small donors' total contributions (See Bouton et al. 2018). 
hence total) small contributions by the same proportion $m$ for both candidates, it has no effect on the relative position of the two candidates, nor on election probabilities. Matching subsidies may affect outcomes for other specifications of the contest success function, but the mechanism behind Proposition 5 makes clear why a general matching subsidy will not have a major effect. Analogously, there is no reason to anticipate that it should systematically increase or decrease individual contributions.

On the other hand, a matching subsidy that only applies to contributions below a certain level will generally have an effect. ${ }^{27}$ If the aggregate amount of matched contributions (including the matched subsidy) rises, contributions of those above the matching threshold will decrease. The overall impact on the election can then go either way, depending on which candidate has the largest support among those who contribute below the threshold.

Turning to taxes on contributions, making them dependent on the size of the contribution acts like a negative conditional matching subsidy. Since contributions depend positively on income, this would be like a differential tax on contributions, that is a function of income. Such a tax has the possibility of reducing-or even eliminating-the effect of income on contributions:

Proposition 6 A progressive tax on small contributions equal to $\left.\left[y^{\square}\right)^{\theta / 2} \square 1\right] s_{P}^{i}$ removes the effect of income inequalities from equilibrium small contributions.

The tax considered in Proposition 6 increases with income in such a way that all donors, rich and poor, eventually face the same marginal cost of contribution. As a consequence, the size of individual contributions depends only on preference intensity (and the features of the electoral environment, such as the closeness of the race).

Though such a tax may seem distant from what is observed in current campaign finance regulations across countries, a regulation broadly mimicking such a policy was actually in place in the U.S. between 1972 and 1986 (Cmar 2005). It is still in line with existing tax laws, for example in the U.S., in the following sense. Suppose campaign contributions were deductible from income tax liabilities (including perhaps a subsidy as in the footnote 27, that is, "negative deductibility"), but where the allowed deduction was a decreasing function of income. In the United States, for example, allowed itemized deductions as a whole fall with income for high income taxpayers, with deductions in specific categories

\footnotetext{
${ }^{27}$ In New York City campaigns, for example, donations up to $\$ 175$ from New York City residents are matched at a rate of 6:1. In 2013, small donations and matching funds accounted for 71 percent of the individual contributions in the city's elections. See https://nyccfb.info/program/impact-of-public-funds
} 
differentially limited by income. Suppose further that an income-adjusted deductibility specifically for political contributions as described in the sentence above were combined with an increase in tax rates overall. The net effect would be a tax on campaign contributions that increases with the size of the contribution. For examples of similar tax incentives in various U.S. States, see Cmar (2005) and Magleby et al. (2018).

The next question is of course the political feasibility of such a change. Any proposal framed as a tax on contributions that increases with income would have little prospect of being adopted in the U.S. In contrast, deductibility of contributions that gets phased out as income increases should be far more politically viable. For a thorough discussion of the feasibility and implementability of such a federal tax (or tax credit), see Rosenberg (2002) and Cmar (2005).

\section{Large Donors}

We now consider "large" donors who make contributions in an early stage of the campaign, before small donors enter in. There are therefore two stages in the campaign: in the first, "large" donors make contributions; in the second, "small" donors give to the campaign.

The sequential nature of large and then small donations is consistent with the observation that collecting a large number of small contributions requires a more developed infrastructure (and hence financing the construction of this infrastructure) than collecting a small number of large contributions. (See, for example, the discussion in Magleby et al. 2018). Thus, it is not surprising that even though small contributions play a major role in campaign finance today, candidates tend to tap wealthier donors first. As Magleby et al. (2018, p. 248) write, "In fact, almost every campaign in 2008 and 2012 received larger donations earlier and smaller donations later." (See also their figure 8.2 on the declining average donation size as a campaign progresses.) Similarly, EMILY's list recognized at its founding that early money was crucial to a campaign, where successful fund-raising early in the race aids in attracting other donors later on. EMILY is an acronym for Early Money is Like Yeast, i.e. it makes the dough rise: ${ }^{28}$ early and large contributions allow a campaign to "get off the ground".

Note further that a first-stage donor takes into account the effect of her contribution on the behavior of second-stage donors. Conversely, a second-stage donor is one who assumes

\footnotetext{
${ }^{28}$ https://www.emilyslist.org/pages/entry/our-history
} 
his contribution has no effect on the behavior of other donors. Hence, second-stage donors are "small" not simply perhaps in the size of their contributions, but crucially in the fact that they do not internalize any effects they have on other donors. (Second-stage donors still differ in their income, so that some donations can be large relative to others, but such donations are small relative to total second-stage donations.)

Large donors may be driven by at least two different motives: an influence motive, that is, a desire to affect a candidate's policy platform, and an electoral motive, similar to small donors. Hence, contributions of the first-stage donor may affect small donor decisions in two ways: (i) positively, as small donations would have less of an effect if a large "campaign-starting" donation had not been made; (ii) negatively, as the influence effect moves policy away from the small donors' preferred policy. To disentangle the effects of these two motives, we analyze them in isolation, before discussing their combined effect. In each case, the focus is mainly on the interactions with small donors.

\subsection{Large Donor: Influence Motive}

Here, we focus on a pure influence motive and assume away the direct effects of large donors on electoral prospects. Hence, all electoral effects are mediated by the reactions of small donors, which is the connection we want to scrutinize. ${ }^{29}$ Direct electoral effects will be considered below in section 4.2 .

\subsubsection{Conceptual setup}

There is of course a significant literature on the "trade" of contributions for policy influence (Grossman and Helpman 1994, Prat 2002, Coate 2004a,b, Drazen and Limão 2008, among others). Our interest is not in the mechanism of such a trade per se (the papers just mentioned model this), but in the possible implications of such influence buying on the behavior of small donors. This would include how their choice problem itself is affected, as well as how the level of small donations, both individually and in aggregate, would be impacted.

The real-world relevance of such effects turn on two observations: first, the extent to which participants in the electoral process perceive that large contributors "bias" policy away from their bliss point; and, second, the possibility that influence-buying by large

\footnotetext{
${ }^{29}$ In our model, candidates are passive: it is large, early donors who are aware of such effects, and adjust their behavior accordingly.
} 
donors affects small-donor behavior. On the first, there can be no doubt of this, and it has been widely accepted as a part of existing models of influence buying. ${ }^{30}$

On the second point, candidates rejecting large donations in favor of small ones is a clear trend. For example, in the 2018 US campaign cycle, over 140 candidates campaigning for Congress "pledged to at least reject corporate PAC funding, and a handful of them have rejected all PAC money". ${ }^{31}$ Uniformly, they chose to rely on small donations. Note, however, that the argument is more than simply relying on small donations. By rejecting PAC money these candidates wanted to signal that if elected, their policy choices would not be influenced by large donors wanting to buy policy favors. And, crucially, the expectation is that such a signal would encourage small donors, as evidence strongly suggests. (The discussion in the article referenced in the previous footnote is but one example.) Conversely, the effectiveness of the charge by small-donation financed campaigns that opponents have been bought by large donors (for example, in a wine cellar in Napa Valley ${ }^{32}$ ) provides evidence of a strong reaction by supporters of opposing candidates.

\subsubsection{Formalization of the Influence Motive}

We formalize the above by considering a "large" donor who must choose her level of contributions $R_{A}$ to candidate $A$. We treat the equivalent contribution $R_{B}$ as given for simplicity. ${ }^{33}$ This large donor is a Stackelberg leader: she moves before small donors, who will observe $R_{A}$ before choosing their own contributions.

Since this section focuses on the influence motive, we let the contributions $R_{A}$ induce candidate $A$ to modify her platform in a way that benefits such large donors and increases her utility differential between electing candidate $A$ over $B$. Formally, denoting this utility differential $\Delta\left(R_{A}\right)$, we have $\partial \Delta\left(R_{A}\right) / \partial R_{A}>0$. For tractability, we simply assume the

\footnotetext{
${ }^{30}$ Becker (1983) is perhaps the first model, albeit in reduced form. Grossman and Helpman (2001), Prat (2002), Coate (2004a,b) and others all stress how special interest group contributions bias policy away from social welfare.

${ }^{31}$ https://eu.usatoday.com/story/news/politics/2018/06/17/more-democrats-limiting-even-rejectingspecial-interest-donations/702907002/

${ }^{32}$ https://www.nytimes.com/2019/12/19/us/politics/wine-cave.html

${ }^{33}$ We could also study the strategic interactions between this rich donor, and another one who supports $B$, as in the literature on "lobby competition" (Grossman and Helpman 1994), or consider multiple donors on each side of the political spectrum. However interesting, such interactions have already been studied and integrating all of them into this model would blur our focus, which is on the interactions with small donors and whether it modifies or reinforces previous findings.
} 
following functional form:

$$
\Delta\left(R_{A}\right)=\delta+\phi R_{A}^{\beta}, \text { with } \beta \in(0,1),
$$

and where $\delta>0$ captures how much the large donor prefers $A$ over $B$ before any policy favor, and $\phi$ captures the sensitivity of the utility differential to $R_{A}$ (it can, for instance, represent the bargaining power of the influence-buying donor, as studied in Drazen and Limão 2008).

A key implication of influence buying is that the induced policy distortions happen at the expense of the rest of the electorate. Formally, the value $v_{A}$ that small $A$ donors put on $A$ 's election falls: $d v_{A} / d R_{A} \leq 0$. By the same token, small $B$ donors put a higher value on $B$ getting elected: $d v_{B} / d R_{A} \geq 0$. Being a Stackelberg leader, early large donors take the (re)actions of Stackelberg followers-small donors-into account.

Given this section's focus on a pure influence motive, winning probabilities are still defined by (1). (Later, we generalize $\pi_{A}$ to the case in which contributions by large donors impact winning probabilities directly.) From Proposition 1, it is straightforward to show that:

$$
\begin{aligned}
\pi_{A}^{*}\left(R_{A}\right) & =\left(1+\left(\frac{S_{B}^{*}}{S_{A}^{*}}\right)\right)^{\square 1}=\left(1+\sqrt{\frac{W_{B}}{W_{A}}}\right)^{\square 1}, \text { with } W_{P}=n_{P} \bar{Y}_{P} v_{P}\left(R_{A}\right) \\
& =\left(1+\sqrt{\frac{n_{B} \bar{Y}_{B}}{n_{A} Y_{A}}} \lambda\left(R_{A}\right)\right)^{\square 1}, \text { with } \lambda\left(R_{A}\right)=\sqrt{v_{B}\left(R_{A}\right) / v_{A}\left(R_{A}\right)} .
\end{aligned}
$$

The novelty is that $v_{B} / v_{A}$ is now increasing in $R_{A}$ : this connects influence buying by the large donor, and the small donors' stake in the election.

Let $\lambda^{\prime}\left(R_{A}\right) \equiv d \lambda\left(R_{A}\right) / d R_{A}(>0)$ denote the first derivative of $\lambda$ with respect to $R_{A}$, and focus on the relative change in valuations by small donors, i.e. $\lambda^{\prime}\left(R_{A}\right) / \lambda\left(R_{A}\right)$. The higher is this relative change, the "more reactive" small donors are to influence buying. For the sake of interpretability in representing this reaction, we summarize it parametrically as:

$$
\bar{\lambda}:=\lambda^{\prime}\left(R_{A}\right) / \lambda\left(R_{A}\right), \forall R_{A} .
$$

Letting $y^{l}$ denote the income of the large donor, her optimization problem is:

$$
\max _{R_{A}} \pi_{A}^{*}\left(R_{A}\right) \times \Delta\left(R_{A}\right) \square \frac{\left(R_{A}\right)^{2} / 2}{\left(y^{l}\right)^{\theta}} .
$$




\subsubsection{Equilibrium Analysis}

We are now in a position to characterize the equilibrium and prove some comparative statics. Some of these comparative statics are in line with previous results in the literature, while those reflecting the interaction of large and small donors are novel:

Proposition 7 For $\pi_{A}^{*}$ as defined in (9), there is a unique equilibrium $R_{A}^{*}>0$ such that:

(i) $R_{A}^{*}$ is weakly increasing in $\phi$, and $y^{l}$;

(ii) $R_{A}^{*}$ is weakly decreasing in $\delta, \bar{\lambda}$, and $\frac{n_{B} \bar{Y}_{B}}{n_{A} \bar{Y}_{A}}$.

To understand the comparative statics, it is useful to examine the first order condition associated with (10):

$$
\frac{R_{A}}{\left(y^{l}\right)^{\theta}}=\pi_{A}^{*} \frac{\partial \Delta\left(R_{A}\right)}{\partial R_{A}}+\frac{d \pi_{A}^{*}}{d R_{A}} \Delta\left(R_{A}\right) .
$$

The LHS of (11) is the direct marginal cost of contributions, which is weakly decreasing in the large donor's income $\left(y^{l}\right)$. This drives the result that $R_{A}^{*}$ is weakly increasing in $y^{l}$.

On the RHS of (11), the first term captures the direct benefit of contributing to $A$ : conditional on $A$ winning, a higher contribution translates into a more valuable policy. This implies that our model recovers the standard prediction of a "bandwagon effect" for large donors: a higher $\pi_{A}^{*}$ increases the marginal benefit of her contribution $R_{A}$, everything else equal. This is because the more likely one's preferred candidate is to win, the larger is the value of moving her platform in the desired direction.

However, everything else is not equal, and this modifies the behavior of the large donor. This is captured by the second term on the RHS of (11), which is the indirect cost of contributing. It increases with the small donors' reaction to $R_{A}$. Interestingly, this reaction by small donors reinforces the "standard" bandwagon effect discussed above. Remember that the effect of a small contribution is maximal when the election is close, i.e. when $\pi_{P}^{*}$ is close to $1 / 2$. Thus, a given reaction by small donors to a large donor's contribution has a larger electoral impact when $\pi_{A}$ is low (close to $50 \%$ ) than when it is large. The larger the impact, the less the large donor contributes in equilibrium. This means that the small donors' reaction steepens the bandwagon effect for the large donor.

This indirect cost of $R_{A}$ affects many of our comparative statics. For instance, it is the sole driver of the effect of $\delta$, i.e., how much the large donor prefers $A$ over $B$ before any policy favor. The higher $\delta$, the less such a donor contributes in equilibrium. This is because, when she prefers $A$ over $B$ more, a defeat of $A$ becomes more costly. She 
then prefers not to extract too many favors in order not to alienate small donors. The effect of $\bar{\lambda}$, the percentage change in intrinsic support in favor of the opponent by small donors, goes through a similar mechanism. The larger $\bar{\lambda}$, the bigger the electoral pushback resulting from favor buying, hence the lower $R_{A}^{*}$.

The effects of $\phi$ and $\frac{n_{B} \bar{Y}_{B}}{n_{A} \bar{Y}_{A}}$ are a combination of the two terms on the RHS of (11). Consider the effect of $\phi$, the parameter capturing the effectiveness of the contributions of the influence-buying donor. A higher $\phi$ means a higher direct return on contributing (higher first term), but also a higher indirect cost of contributing because, due to the increased effectiveness of contributions, the large donor has stronger preferences for $A$. Proposition 7 shows that the first effect always dominates. For the effect of $\frac{n_{B} \bar{Y}_{B}}{n_{A} Y_{A}}$, which measures the balance in support for the two candidates among small donors, the two terms reinforce one another. A higher $n_{B} \bar{Y}_{B} / n_{A} \bar{Y}_{A}$ reduces the probability that $A$ wins (smaller benefit of contributing), and increases the effect of the reaction by small donors because the election is closer (larger indirect cost of contributing).

This indirect cost of large contributions is also relevant for Tullock's (1980) "missing money" puzzle. The self-moderation of large donors meant to limit the electoral "backlash" that we identify here may be an additional reason why money ostensibly used to buy influence is not more abundant in electoral politics. Even if there is a significant direct marginal benefit of contributing (as suggested by various empirical estimates, see Avis (2018) and references therein), large donors may prefer not to increase their contributions because the indirect cost offsets this effect. This indirect cost also complements the results in Coate (2004): the negative electoral effect of favors to large donors can come from a direct reaction of voters (as in Coate) or through a reaction of small donors who then affect voters (as in our model). Moreover, our result shows that the presence of small donors can make the backlash so strong that it reverses the electoral boost of large contributions.

These results produce at least two empirical predictions. First, while contributions by large, early donors have an indeterminate effect on total small contributions $\left(S_{A}+S_{B}\right)$, they have an unambiguous effect on small contributions to both candidates who receive these large contributions and their opponents. That is, the effect of $R_{A}$ on $S_{A}$ is negative, while the effect of $R_{A}$ on $S_{B}$ is positive. We are not aware of existing empirical evidence relevant to that prediction. Second, note the contrast between the underdog effect for small donors and a strong bandwagon effect for the large donors who care about influence. This finds empirical support in Bonica (2016, figure 2): PACs contribute almost exclusively, 
and lobbies and Fortune 500 executives largely, to ex post winners. Remember that, by contrast, barely 48 to $55 \%$ of small contributions flow to ex post winners (see Section $3.2 .2)$.

\subsubsection{Campaign Finance Laws}

What are the effects of campaign contribution caps when we include large donors with a first-mover advantage? Consider first the case in which caps on individual contributions constrain small donors only. That is, large donors can find ways to influence policy that are not affected by legal limitations, for example, via lobbying expenditures or contributions to political action committees (PACs).

Suppose that the income distribution is identical for the small $A$ and the small $B$ donors: $f_{A}\left(y^{g}\right)=f_{B}\left(y^{g}\right)$ for every income group $g$. Candidate $A$ draws her advantage from having a larger number of small donors. In that case:

Proposition 8 Consider a cap on individual contributions by small donors. As the cap starts binding, contributions $R_{A}^{*}$ by the large donor increase discontinuously.

The intuition is that as soon as the cap starts binding on small $B$ donors, the latter can no longer react to $R_{A}$ by further increasing their own contributions. Thus, although the just-binding cap does not affect the level of small contributions, it does reduce the sensitivity of small $B$ donors: this produces a discrete drop in $\bar{\lambda}$. Hence, the optimal contribution of the large donor not only rises; it does so by a discrete amount.

This result is stronger than the critique that if large donors can circumvent limitations on contributions, such limitations will not reduce their disproportionate influence. It shows that, once the interactions between large and small donors are taken into account, some caps may have an effect opposite to the intended one. They may increase influence buying, a possibility that cannot be captured by analyses that ignore large-small interactions.

Consider now a cap specifically on what large donors can give, hence on their ability to influence policy. This was certainly one of the intents of the McCain-Feingold Act regulating contributions by corporations or labor unions, subsequently overturned in the controversial "Citizens United" decision. Many other countries, such as France in 1995, banned contributions by corporations and other legal entities, but not private citizens. ${ }^{34}$

\footnotetext{
${ }^{34}$ Law $95-65$ of the 19th of January 1995, modifying Art. 52-8 of the electoral code. See: https://bit.ly/2Um4GCu.
} 
We find that such a restriction to limit the influence of large donors on campaign platforms increases the probability that their preferred candidate gets elected:

Proposition 9 Consider a law that limits the contribution of large donors to A. As that constraint becomes increasingly binding, candidate A becomes more likely to win.

Proof. Immediate from the fact that $S_{A}^{*}\left(R_{A}\right) / S_{B}^{*}\left(R_{A}\right)$ is strictly decreasing in $R_{A}$.

The rationale for this effect is straightforward. Remember that we are still considering the case in which contributions by large donors only buy influence and do not have any direct effect on winning probabilities. In this case, such contributions produce a relative drop in the small contributions to candidate $A$, and hence lower her probability of winning; a cap reverses that effect.

This is another case in which legislation may have unintended consequences. Limitations on contributions by large donors are meant to reduce not only their influence on policy after the election - as stressed by the models of influence discussed above - but also their influence on election outcomes. Proposition 9 identifies a trade-off between the two objectives. For example, a key provision of the McCain-Feingold Act prohibited "electioneering communications" defined as broadcast ads within 60 days of a general election paid for by a corporation, non-profit issue organization, or union. Proposition 9 shows that, when effective, such prohibition should boost small donors' contributions for the party most affected by the cap, which can enhance its electoral support. For the sake of the example, imagine that contributions from corporations go mainly to a right-wing party. Capping their contributions does make the right-wing party less radical, but it also increases its probability of winning the election. Hence, the implemented policy may move to the right.

\subsection{Large Donor: Electoral Motive}

So far, we focused on the case in which a candidate's probability of winning only depends on the contributions received during the later phase of the campaign, which we defined as "small". While this assumption is restrictive, it allowed us to identify the effects of a "pure" influence motive. Here, we turn to the other main reason why candidates tend to accept early contributions from large donors: these can help set up their campaign infrastructure or, more generally, be used to boost their electoral prospects. 


\subsubsection{Formalization of the Electoral Motive}

To focus on a pure electoral effect, we shut down the influence channel in this section. That is, we set $\Delta\left(R_{A}\right)=\Delta, \forall R_{A}$. Conversely, we now allow both the early/large and the small donors' contributions to influence winning probabilities. Capturing this electoral effect for large donors requires only a minimal modification of our original set-up. Consider the same model as in Section 3.1, but let the contest success function become:

$$
\pi_{P}(Q)=\frac{Q_{P}}{Q_{A}+Q_{B}}, \text { with } Q_{P}:=q\left(R_{P}, S_{P}\right)
$$

with $\partial q / \partial R_{P}>0$ and $\partial q / \partial S_{P}>0$, where we retain the assumption that contributions $R_{P}$ are made before aggregate $S_{p}$. We can think of $Q_{P}$ as a candidate's financial capacity, which is a strictly increasing function of $R_{P}$ and $S_{P}$. That is, contributions by both large and small donors positively affect winning probabilities. We also assume decreasing returns to each type of contribution: $\partial^{2} q / \partial R_{P}^{2} \leq 0$ and $\partial^{2} q / \partial^{2} S_{P} \leq 0$, so that possible convexities in the winning probability are still entirely captured by the parameter .

Given that the large donor is a Stackelberg leader, she will need to take account of the small donors' reaction function. Obviously, we cannot obtain closed-form solutions for any function $q$. For this reason, this section focuses on the Cobb-Douglas aggregator function: ${ }^{35}$

$$
q\left(R_{P}, S_{P}\right)=R_{P}^{\alpha} S_{P}^{1 \square \alpha}
$$

We will return to a general $q$ function in Section 4.3, where we combine the influence and electoral effects.

\subsubsection{Equilibrium Analysis and Campaign Finance Laws}

Solving by backward induction, it is easy to show that the equilibrium in small donors contributions, for a given $R_{A}$, is:

$$
\begin{aligned}
& \left(S_{A}^{*}, S_{B}^{*}\right)=\left(\sqrt{(1 \square \alpha) \pi_{A}^{*} \pi_{B}^{*} W_{A}}, \sqrt{(1 \square \alpha) \pi_{A}^{*} \pi_{B}^{*} W_{B}}\right), \\
& \text { implying }: \quad \pi_{A}^{*}=1 /\left(1+\left[\left(\frac{R_{A}}{R_{B}}\right)^{\alpha}\left(\frac{W_{A}}{W_{B}}\right)^{\frac{1 \square \alpha}{2}}\right]\right)=1 \square \pi_{B}^{*} .
\end{aligned}
$$

\footnotetext{
${ }^{35}$ If instead the aggregator function displayed strategic substitutabilities (respectively complementarities), $S_{P}$ would be decreasing (resp. increasing) in $R_{P}$. See Section 4.3 for the general case.
} 
The problem of the large donor to candidate $A$ then becomes:

$$
\max _{R_{A}} \frac{\delta}{1+\left[\left(\frac{R_{A}}{R_{B}}\right)^{\alpha}\left(\frac{W_{A}}{W_{B}}\right)^{\frac{1 \square \alpha}{2}}\right]^{\square}} \square \frac{R_{A}^{2}}{2\left(y^{l}\right)^{\theta}},
$$

and her first order condition:

$$
\alpha \delta \quad \pi_{A}\left(1 \square \pi_{A}\right)=\frac{R_{A}^{2}}{\left(y^{l}\right)^{\theta}} .
$$

This FOC is similar to the one we found for small donors. Hence: ${ }^{36}$

Proposition 10 When the large donor's contributions are only motivated by the electoral motive, there exists a unique equilibrium $R_{A}^{*}>0$ such that:

(i) $R_{A}^{*}$ is increasing in $\delta$ and $y^{l}$;

(ii) $R_{A}^{*}$ is decreasing in $\frac{W_{A}}{W_{B}}$ iff $\frac{R_{A}^{*}}{R_{B}}<\left(\frac{W_{B}}{W_{A}}\right)^{\frac{1 \square \alpha}{2 \alpha}}$, i.e. $\pi_{A}^{*}<1 / 2$.

In essence, this proposition shows that the results on small donors are robust to introducing dynamic electoral effects in the model. For instance, the effects of preference intensity $(\delta)$ and income $\left(y^{l}\right)$ are identical to the small donors' case. The effect of $\frac{W_{A}}{W_{B}}$ is also similar but with a twist: what matters is the combined effects of $\frac{R_{A}^{*}}{R_{B}}$ and $\frac{W_{A}}{W_{B}}$ on election closeness. When $\frac{R_{A}^{*}}{R_{B}}<\left(\frac{W_{B}}{W_{A}}\right)^{\frac{1 \square \alpha}{2 \alpha}}, A$ is the overall runner-up. In this case, an increase in $A$ 's advantage among small donors makes the election closer, which stimulates initial contributions by the large donor. The opposite holds when $\frac{R_{A}^{*}}{R_{B}}>\left(\frac{W_{B}}{W_{A}}\right)^{\frac{1 \square \alpha}{2 \alpha}}$, in which case $A$ is the overall front-runner. This effect is closely related to the underdog effect for small contributions discussed above. We are not aware of any empirical work exploring this interaction.

From Proposition 10, it is also straightforward that a cap on small contributions could lead to an increase in contributions by the large donor. By Corollary 1, this happens when the cap makes election closer. Conversely, combining Propositions 1 and 10 shows that capping large donors will impact small contributions, and the direction of the effect will again depend on whether it makes the election closer. For instance, a cap on $R_{A}$ leads to

\footnotetext{
${ }^{36}$ Beyond the Cobb-Douglas case, if $R$ and $S$ become substitutes, then $R_{A}$ will be lower than in the Cobb-Douglas case, since every additional dollar of contribution by the rich translates into a reduction in contributions by small $A$ donors. Conversely, if the function $q$ displays complementarities between $R$ and $S$, contributions by the rich $A$ stimulate additional contributions by the small $A$, which increases the rich's "return on contribution".
} 
an increase in small donations (to both candidates) when $A$ has more support among both small and large donors.

\subsection{Large Donors: Both Motives Combined}

These influence and electoral motives can now be combined to get a sense of how the results in Propositions 7-9 interact with that of Proposition 10. We saw that the direction of some of the predictions are reversed between these. Thus, intuitively, while key mechanisms remain valid, eventual predictions are a priori less clear-cut.

Formally, let us return to a generic function $q\left(R_{P}, S_{P}\right)$, as introduced in (12). The equilibrium behavior of small donors can then be implicitly determined through the FOC:

$$
\begin{aligned}
S_{P}= & \sqrt{W_{P} \quad \pi_{A}\left(1 \square \pi_{A}\right) \eta_{S_{P}}^{Q_{P}}}, \\
& \text { where } \eta_{S_{P}}^{Q_{P}} \equiv \frac{\partial Q_{P}}{\partial S_{P}} \frac{S_{P}}{Q_{P}},
\end{aligned}
$$

where $\eta_{X}^{Y}$ is the elasticity of variable $Y$ with respect to $X$. The only difference with the FOC in the initial model with only small donors (Section 3.2) is that, there, $\eta_{S_{P}}^{Q_{P}}$ was equal to 1. In the Cobb-Douglas model we just discussed (Section 4.2), it was $1 \square \alpha$. By contrast, in this generalized setup, $\eta_{S_{P}}^{Q_{P}}$ can be larger or smaller than 1 , and may vary with the contributions of the large donor. In particular, strategic complementarities

would imply that $\eta_{S_{A}}^{Q_{A}}$ is increasing in $R_{A}$, and decreasing in the presence of strategic substitutabilities.

Moving to the first stage of the contribution game, the large donor $A$ must take account of both direct and indirect effects of her contribution:

$$
\begin{aligned}
\frac{R_{A}}{\left(y^{l}\right)^{\theta}} & =\pi_{A} \frac{\partial \Delta\left(R_{A}\right)}{\partial R_{A}}+\frac{d \pi_{A}}{d R_{A}} \Delta\left(R_{A}\right), \\
\text { where } & : \quad \frac{d \pi_{A}}{d R_{A}}=\frac{\pi_{A}\left(1 \square \pi_{A}\right)}{R_{A}}\left[\eta_{R_{A}}^{Q_{A}}+\eta_{S_{A}}^{Q_{A}} \eta_{R_{A}}^{S_{A}} \square \eta_{S_{B}}^{Q_{B}} \eta_{R_{A}}^{S_{B}}\right] .
\end{aligned}
$$

The left-hand side of (15) is, as before, the marginal cost of contributions, which is decreasing in the income of the large donor, $y^{l}$, when $\theta>0$. The first term on the right-hand side captures the direct benefits of buying favors. The second term is the (now direct and indirect) effects of $R_{A}$ on the probability of winning, given $\Delta\left(R_{A}\right)$. Turn to (16): the first term between square brackets captures the direct electoral effects of the large donor's contribution. The second and third terms capture the small donors' reactions, mediated 
through the impact of their contributions on the probability of winning $\left(\eta_{S_{P}}^{Q_{P}}\right)$. In contrast with the pure influence case, contributions by the large donor can potentially increase or decrease relative support for $A .^{37}$

While we cannot obtain closed-form solutions, inspection of (15) and (16) leads to several insights. First, note that the two terms on the RHS move in opposite directions with the closeness of the election (i.e., how close $\pi_{A}$ is to $1 / 2$ ): the first term, which captures the influence motive, decreases whereas the second term, which captures both the benefits of the electoral motive and the indirect cost of the influence motive, increases (because $\pi_{A}\left(1 \square \pi_{A}\right)$ is maximized in $\left.\pi_{A}=1 / 2\right)$. This suggests that the influence motive should dominate when the election is lopsided, and the electoral motive should dominate when the election is close. In particular, if the elasticities $\eta_{X}^{Y}$ are all bounded, a sufficient condition for the influence motive to dominate is that $\pi_{A}$ is sufficiently large.

We are not arguing that empirical studies of the influence of money on policy should primarily focus on lopsided elections. Indeed, the influence motive could also dominate in close elections when there are caps on individual contributions by small donors. As we have noted before, such a cap reduces-potentially eliminates-the ability of small donors to push back against the favors obtained by large donors. If that reduction is large enough, the influence motive could also dominate in close elections.

Second, condition (15) highlights that a shift in (expected) support among small donors should have an opposite effect on a large donor who contributes to the candidate who is ahead (typically, the incumbent) rather than the one who is behind (typically, the challenger). Consider an election that becomes increasingly lopsided among small donors, producing a drop in both $\pi_{A}\left(1 \square \pi_{A}\right)$ and in $1 \square \pi_{A}$. The first drop tilts the large donor who supports $A$ towards additional contributions for favors, and less for electoral purposes. The effect on $R_{A}$ is thus indeterminate. For a large donor who is a supporter of $B$, the total effect would be unambiguous: she would reduce her contributions on both counts.

\footnotetext{
${ }^{37}$ The Cobb-Douglas benchmark of the previous section implied that the second and third terms added up to zero. Therefore, if the aggregator function $q$ displays strategic complementarities, larger contributions by $A$ would reduce (or possibly reverse) the underdog effect identified for electorally motivated contributions. That is, the second and third terms would add up to a positive amount, inducing higher contributions $R_{A}^{*}$ than in the Cobb-Douglas case. The opposite holds in the case of strategic substitutabilities.
} 


\section{A Demand-Side Model of the Electoral Motive}

One may argue that modeling small donors as highly calculating and perfectly informed actors lacks realism. In particular, small donors may miscalculate the impact of their contribution, or be responding to basic psychological motivations or to their candidates' requests (Mutz 1995, Rogers et al. 2017). For example: donors may mechanically react to media attention and/or candidate fund-raising efforts. In this section, we show that our results about small donors' behavior (Section 3.1) are fully consistent with such behavioral motivations. What is more, the amount of effort candidates put into raising funds from small donors suggests that candidates are quite aware of this.

Here, we show that a reasonable functional representation of behavioral responses leads to the same first-order conditions, and hence identical results as in the model with instrumental small donors. Hence, whether individual behavior is driven by rational donors who are instrumentally motivated, or by the strategic behavior of candidates, the implications of electoral considerations for contributions as identified in the previous sections hold.

To formalize this point, we assume in this section that small donors mechanically respond to party requests for contributions. Candidates, on their side, need to exert a costly effort in order to induce their supporters to contribute to their campaign. This change in perspective transforms our model into a "demand-side" model in which candidates, who care about winning the election, are the strategic actors, rather than a "supply-side" model in which donors were the strategic actors.

Consider $n_{P}$ donors of type $P$, distributed in income classes $y^{1}<\ldots<y^{G}$ according to the a distribution function $F_{P} y^{i}$ ), that satisfies the same assumptions as in Section 3.1. We assume that donor $i$ reacts mechanically to his candidate's (costly) fund-raising

effort, denoted $e_{P}^{i}$. His contribution $q_{P}^{i}$ is increasing and concave in both $e_{P}^{i}$ and $y^{i}$. We represent this functionally by:

$$
\begin{array}{ll}
\text { For types } A: & \left.s_{A}^{i}=\left(y^{i}\right)^{\theta} v_{A} e_{A}^{i}\right)^{\frac{1}{2}} \\
\text { For types } B: & \left.s_{B}^{i}=\left(y^{i}\right)^{\theta} v_{B} e_{B}^{i}\right)^{\frac{1}{2}},
\end{array}
$$

where $\theta$ parameterizes the donors' elasticity of contributions exactly like in the instrumental model. The Cobb-Douglas specification is chosen both for simplicity and to relate to the main model.

Candidates choose $e_{P}^{i}$ to maximize their probability of winning net of the cost of fund- 
raising (where, for simplicity, we let the cost of soliciting a donor be $e_{P}^{i}$ ):

$$
\begin{array}{r}
P \text { maximizes }: \frac{S_{P}}{S_{A}+S_{B}} \square \sum_{i} e_{P}^{i}, \\
\text { s.t. } S_{P}=\sum_{i} s_{P}^{i} .
\end{array}
$$

It follows that:

$$
\left.e_{P}^{i *}=\left(\frac{d \pi_{P} / d S_{P}}{2}\right)^{2} y^{i}\right)^{\theta} v_{P} .
$$

Substituting these equilibrium levels of candidate effort into the donors' contribution functions (17) and (18) yield:

$$
\begin{aligned}
s_{A}^{i *} & \left.=\frac{d \pi_{A} / d S_{A}}{2} y^{i}\right)^{\theta} v_{A}, \\
s_{B}^{i *} & \left.=\frac{d \pi_{B} / d S_{B}}{2} y^{i}\right)^{\theta} v_{B},
\end{aligned}
$$

which is identical (but for the factor $\frac{1}{2}$ ) to (3) and (4).

In other words, there exists some form of response by behavioral donors and strategic candidates such that the equilibrium level of individual and aggregate contributions are the same as with strategic donors and passive candidates. Hence, although it is a perfectly valid empirical question to ask, "How rational are small donors?", allowing them to be "behaviorally motivated" rather than fully rationally instrumental does not qualitatively change our findings on how electoral motives (here on the part of candidates) influence individual contributions, nor on how economic variables and legal constraints would influence total contributions and the feedback loops between aggregate and individual contributions.

\section{Conclusions}

Small contributions to political campaigns have become extremely important. Conventional wisdom is that such contributions are a consumption good to the donors. In large part this is a conclusion by default, the basic reasoning being that because each donation is so small relative to total campaign donations, small donors cannot be motivated either by an attempt to buy influence nor by any effect they may have on election outcomes. In this paper, we instead argue that contributions by small donors can be better explained by an electoral motive, either on the part of donors (for instrumental or behavioral reasons), or on the part of candidates. 
Our model of small donors predicts patterns of contributions that are in line with a number of empirical findings in the literature, and that contrast with explanations of contributions relying on a simple consumption motive or on an influence motive. There is, for instance, a "closeness" effect in which equilibrium contributions increase when the support for the two candidates is more even, as well as an "underdog effect", whereby equilibrium relative contributions for the advantaged candidate are smaller than their underlying advantage. (These are in contrast to a "bandwagon" effect under an influence motive, and no predicted effect in the simple consumption motive.) The model also makes novel predictions about the effects of increases in income inequality on campaign contributions and election outcomes depending on the source of inequality.

Our model gives insights into the effects of campaign finance laws. We find that a cap on individual contributions affects all donors, including those not directly hit by the cap. This introduces complications for empirical analyses. The cap generally favors the candidate with the largest number of donors and works against the candidate with the richest donors, but these effects are not necessarily monotonic. Instead, matching subsidies have limited, or no effects. It is possible to eliminate the effects of income inequalities on campaign contributions by implementing an income-contingent tax on contributions.

We also study the interactions between small and large donors. We consider the problem of a large donor who contributes to a candidate at an early stage of the campaign, when candidate platforms are potentially still fluid, and before small donors make their decisions. We allow for the donor to be motivated both by a desire to curry favors, that is, an influence motive, and to influence the outcome of the election, that is, an electoral motive. This augmented model produces various additional insights. First, we identify a new indirect cost of contributing that arises specifically from the interactions with small donors. This induces large donors to moderate their contribution, and their request for favors. Second, we find that policy favors should be more prevalent in lopsided elections. Third, due to interactions between small and large donors, cap on contributions can have additional unintended effects. For instance, capping small contributions during the electoral campaign, while not effectively capping large donors may end up boosting the large donors' requests and favor extraction.

We view this paper as a first step to better understanding small political contributions by moving away from the common view that they must be a consumption good for the donors. As discussed in the paper, we believe an electoral motive for such contributions 
is not only theoretically sensible, it also can better explain several empirical regularities, as well as provide some guidance to further empirical work. 


\section{References}

[1] Ashworth, Scott (2006) "Campaign Finance and Voter Welfare with Entrenched Incumbents", American Political Science Review, 100(1): 55-68.

[2] Agranov, M., J. Goeree, J. Romero, and L. Yariv (2018). What Makes Voters Turn Out: The Effects of Polls and Beliefs, Journal of the European Economic Association, 16(3): 825-856.

[3] Ansolabehere, S., J. de Figueiredo, and J. Snyder (2003). Why Is There so Little Money in U.S. Politics?, Journal of Economic Perspectives, 17(1): 105-130.

[4] Avis, E. (2018). Interest Groups, Campaign Finance and Policy Influence: Evidence from the U.S. Congress, mimeo.

[5] Barber, M. (2016). Donation Motivations: Testing Theories of Access and Ideology, Political Research Quarterly, 69(1): 148-159.

[6] Barber, M., B. Canes-Wrone, and S. Thrower (2017). Ideologically Sophisticated Donors: Which Candidates Do Individual Contributors Finance?, American Journal of Political Science, 61(2): 271-88.

[7] Baron, D. (1994). Electoral Competition with Informed and Uninformed Voters, American Political Science Review, 88: 33-47.

[8] Becker, G. (1983). "A Theory of Competition Among Pressure Groups for Political Influence," Quarterly Journal of Economics 98 (3): 371-400.

[9] Bekkouche, Y. and J. Cagé (2019). The Heterogeneous Price of a Vote: Evidence from France, 1993-2014, CEPR Discussion Paper, 12614.

[10] Benoit, K. and M. Marsh (2008). "The Campaign Value of Incumbency: A New Solution to the Puzzle of Less Effective Incumbent Spending", American Journal of Political Science, 52: 874-90.

[11] Bertrand, M., M. Bombardini, and F. Trebbi (2014). Is It Whom You Know orWhat You Know? An Empirical Assessment of the Lobbying Process. American Economic Review, 104(12): 3885-3920.

[12] Bombardini, M. and F. Trebbi (2011). Votes or Money? Theory and Evidence from the US Congress, Journal of Public Economics, 95(7-8): 587-611.

[13] Bonica, A. (2014). Mapping the Ideological Marketplace, American Journal of Political Science, 58(2): 367-386.

[14] Bonica, A. (2016). Avenues of Influence: On the Political Expenditures of Corporations and Their Directors and Executives, Business and Politics, 18(4): 367-394. 
[15] Bonica, A., N. McMarthy, K. Poole, and H. Rosenthal (2013). Why Hasn’t Democracy Slowed Rising Inequality? Journal of Economic Perspectives, 27(3): 103-124.

[16] Bonica, A. and H. Rosenthal (2018). Increasing Inequality in Wealth and the Political Expenditures of Billionaires, mimeo.

[17] Bonneau, C. and D. Cann (2011). Campaign Spending, Diminishing Marginal Returns, and Campaign Finance Restrictions in Judicial Elections, Journal of Politics, 73(4): 1267-80.

[18] Brown, C., W. Clifford, L. Powell, and C. Wilcox (1995). Serious money: Fund-raising and contributing in presidential nomination campaigns, Cambridge: Cambridge University Press.

[19] Castanheira, M. (2003). Victory Margins and the Paradox of Voting, European Journal of Political Economy, 19: 817-841.

[20] Chamon, M. and E. Kaplan (2013). The Iceberg Theory of Campaign Contributions: Political Treats and Interest Group Behavior, American Economic Journal: Economic Policy, 5(1):1-31.

[21] Claassen, R. (2007). Campaign Activism and the Spatial Model: Getting Beyond Extremism to Explain Policy Motivated Participation, Political Behavior, 29(3): 369390.

[22] Cmar, T. (2005). Toward a Small Donor Democracy: The Past and Future of Incentive Programs for Small Political Contributions, Fordham Urban Law Journal, 32(443): 101-160.

[23] Coate, S. (2004a). Pareto-improving Campaign Finance Policy. American Economic Review, 94(3): 628-655.

[24] Coate, S. (2004b). Political Competition with Campaign Contributions and Informative Advertising. Journal of the European Economic Association, 2(5): 772-804.

[25] Culberson, T., M. McDonald, and S. Robbins (2019). Small Donors in Congressional Elections. American Politics Research, 47(5): 970-999.

[26] Da Silveira, B. and J. De Mello (2011). Campaign Advertising and Election Outcomes: Quasi-natural Experiment Evidence from Gubernatorial Elections in Brazil, Review of Economic Studies, 78(2): 590-612.

[27] DellaVigna S., R. Durante, B. Knight, and E. La Ferrara (2016). Market-based Lobbying: Evidence from Advertising Spending in Italy, American Economic Journal: Applied Economics, 8(1): 224-56.

[28] Drazen, A. and N. Limão (2008) A Bargaining Theory of Inefficient Redistribution Policies. International Economic Review 49(2): 621-657. 
[29] Enos, R. D., and Fowler, A. (2016). Aggregate effects of large-scale campaigns on voter turnout. Political Science Research and Methods, 1-19.

[30] Epstein, G. and S. Nitzan (2006). The Politics of Randomness, Social Choice and Welfare, 27: 423-433.

[31] Erikson, R. and T. Palfrey (1998). Campaign Spending and Incumbency: An Alternative Simultaneous Equations Approach, Journal of Politics, 60(2): 355-373.

[32] Erikson, R. and T. Palfrey (2000). Equilibria in Campaign Spending Games: Theory and Data, American Political Science Review, 94(3): 595-609.

[33] Esteban, J. and D. Ray (1999). Conflict and Distribution, Journal of Economic Theory, 87: 379-415.

[34] Esteban, J. and D. Ray (2001). Collective Action and the Group Size Paradox, American Political Science Review, 95(3): 663-672.

[35] Feddersen, T. and F. Gul (2015). Polarization and Income Inequality: A Dynamic Model of Unequal Democracy, mimeo.

[36] Feddersen, T. and Sandroni, A. (2006), A Theory of Participation in Elections, American Economic Review PEPP 96: 1271-1282.

[37] Feigenbaum, J.J., and C.A. Shelton (2013). The Vicious Cycle: Fundraising and Perceived Viability in US Presidential Primaries. Quarterly Journal of Political Science $8(1): 1-40$.

[38] Francia, P., P. Herrnson, J. Green, L. Powell and C. Wilcox (2003). The Financiers of Congressional Elections: Investors, Ideologues, and Intimates, New York: Columbia University Press.

[39] Fuchs, E.R., E.S. Adler, and L.A. Mitchell (2000). WIN, PLACE, SHOW. Public Opinion Polls and Campaign Contributions in a New York City Election. Urban Affairs Review, 35(4): 479-501.

[40] Gerber, A. (2004). Does Campaign Spending Work?: Field Experiments Provide Evidence and Suggest New Theory, American Behavioral Scientist, 47: 541-574.

[41] Gordon, S., C. Hafer, and D. Landa (2007). Consumption or Investment: On Motivations for Political Giving, Journal of Politics 69(4): 1057-1072.

[42] Grossman, G., and E. Helpman (1994). Protection for Sale, American Economic Review, 84(4): 833-850.

[43] Grossman, G., and E. Helpman (1996). Electoral Competition and Special Interest Politics, Review of Economic Studies, 63: 265-286. 
[44] Hall, A., and J. Snyder (2014). Information and Wasted Votes: A Study of U.S. Primary Elections, Quarterly Journal of Political Science 10(4): 433-459.

[45] Herrera, H., M. Morelli, and T. Palfrey (2014). Turnout and Power Sharing, Economic Journal, 124(574): F131-F162.

[46] Herrera, H., M. Morelli, and S. Nunnari (2016). Turnout Across Democracies, American Journal of Political Science, 60(3): 607-24.

[47] Hirshleifer, J. (1989). Conflict and Rent-Seeking Success Functions; Ratio vs. Difference Models of Relative Success, Public Choice 63: 101-112.

[48] Jacobson, G. (1980). Money in Congressional Elections. New Haven: Yale University Press.

[49] Jacobson, G. (1985). Money and Votes Reconsidered: Congressional Elections, 19721982, Public Choice, 47: 7-62.

[50] Jia, H., S. Skaperdas, and S. Vaidya (2013). Contest functions: Theoretical foundations and issues in estimation, International Journal of Industrial Organization, 31: $211-22$.

[51] Kartal, M. (2015). A Comparative Welfare Analysis Of Electoral Systems With Endogenous Turnout, Economic Journal, 125(September): 1369-92.

[52] Katz, E., S. Nitzan, and J. Rosenberg (1990). Rent-Seeking for Pure Public Goods, Public Choice, 65(1): 49-60.

[53] Kawai, K. and T. Sunada (2015). Campaign Finance in U.S. House Elections, mimeo.

[54] Kendall, C., T. Nannicini, and F. Trebbi (2015). How Do Voters Respond to Information? Evidence from a Randomized Campaign, American Economic Review, 105(1): $322-53$.

[55] Konrad, K. (2007). Strategy in Contests - an Introduction, WZB-Markets and Politics Working Paper, SP II 2007-01.

[56] Larreguy, H., J. Marshall, and J. Snyder (2018). Leveling the Playing Field: How Campaign Advertising Can Help Non-Dominant Parties, Journal of the European Economic Association, 16(6) :1812-1849.

[57] Levitt, S. (1994). Using Repeat Challengers to Estimate the Effect of Campaign Spending on Election Outcomes in the U.S. House, Journal of Political Economy, 102(4): 777-798.

[58] Lott, J. (2006). Campaign Finance Reform and Electoral Competition, Public Choice, 129: 263-300. 
[59] Magleby, D., Goodliffe, J., and Olsen, J. (2018). Who Donates in Campaigns?: The Importance of Message, Messenger, Medium, and Structure. Cambridge: Cambridge University Press.

[60] Malbin, Michael J. (2013). "Small donors: Incentives, economies of scale, and effects". The Forum. Vol. 11 De Gruyter pp. 385-411.

[61] McCarty, N., K. Poole, and H. Rosenthal (2006). Polarized America, MIT Press, Cambridge, Massachusetts.

[62] Morton, R. and R. Myerson (2012). Decisiveness of Contributors' Perceptions in Elections. Economic Theory, 49: 571-590.

[63] Mutz, D. (1995). Effects of Horse-Race Coverage on Campaign Coffers: Strategic Contributing in Presidential Primaries, The Journal of Politics, 57(4): 1015-42.

[64] Myatt, D. (2015). A Theory of Voter Turnout, mimeo.

[65] Palfrey, T. and H. Rosenthal (1985). Voter Participation and Strategic Uncertainty, American Political Science Review, 79: 62-78.

[66] Prat, A. (2002). Campaign Advertising and Voter Welfare, Review of Economic Studies, 69(4): 999-1017.

[67] Rogers, T. and D. Moore (2014). The Motivating Power of Underconfidence: "The Race is Close but We're Losing". Harvard Kennedy School RWP14-04\%.

[68] Rogers, T., D. Moore, and M. Norton (2017). The Belief in a Favorable Future, Psychological Science, 28(9): 1290-1301.

[69] Rosenberg, D. (2002). Broadening the Base - The Case for a New Federal Tax Credit for Political Contributions, American Enterprise Institute for Public Policy Research.

[70] Schlozman, Kay Lehman, Sidney Verba, and Henry E. Brady (2012). The Unheavenly Chorus: Unequal Political Voice and the Broken Promise of American Democracy. Princeton University Press.

[71] Skaperdas, S. and B. Grofman (1995). Modeling Negative Campaigning, American Political Science Review, 89: 49-61.

[72] Spenkuch, J. L. and D. Toniatti (2018). Political advertising and election outcomes, Quarterly Journal of Economics, 133(4): 1981-2036.

[73] Sprick Schuster, S. (2020). Does Campaign Spending Affect Election Outcomes? New Evidence from Transaction-Level Disbursement Data, Journal of Politics, forthcoming.

[74] Stratmann, T. (1992). Are Contributors Rational? Untangling Strategies of Political Action Committees, Journal of Political Economy, 100(3): 647-664. 
[75] Stratmann, T. (2006). Contribution Limits and the Effectiveness of Campaign Spending, Public Choice, 129: 461-474.

[76] Stratmann, T. (2009). How Prices Matter in Politics: The Returns to Campaign Advertising, Public Choice, 140(3/4): 357-377.

[77] Stratmann, T. and F. Aparicio-Castillo (2006). Competition Policy for Elections: Do Campaign Contribution Limits Matter?, Public Choice, 127: 177-206.

[78] Tullock, G. (1980). Efficient Rent Seeking, In: Buchanan, J., R. Tollison, and G. Tullock (eds.), Toward a Theory of the Rent-Seeking Society, Texas A\&M University Press, College Station: 97-112. 


\section{Appendix}

\section{Appendix 1. Proofs for Section 3.2}

Lemma $1 S_{P}^{*}$ is increasing in $W_{P}, \forall P \in\{A, B\}$. For $S_{A}^{*}>S_{B}^{*}$, $S_{A}^{*}$ is increasing in $W_{B}$, whereas $S_{B}^{*}$ is decreasing in $W_{A}$. For $S_{A}^{*}<S_{B}^{*}, S_{A}^{*}$ is decreasing in $W_{B}$, and $S_{B}^{*}$ is increasing in $W_{A}$.

Proof of Lemma 1. The proof focuses on the case $S_{A}^{*}>S_{B}^{*}$. By symmetry, the complementary case amounts to a labeling swap between $A$ and $B$.

From Proposition 1 and the definition of $\omega$, we have:

$$
S_{A}^{*}=\left(\omega W_{A}^{\rho \square 1}\right)^{\frac{1}{\rho}} \text { and } S_{B}^{*}=\left(\omega W_{B}^{\rho \square 1}\right)^{\frac{1}{\rho}}
$$

Taking derivatives and simplifying yields:

$$
\frac{\partial S_{A}^{*}}{\partial W_{A}}>0 \Leftrightarrow \pi_{A}^{*}<\frac{1}{2}\left(1+\frac{\rho}{)}\right) \text { and } \frac{\partial S_{A}^{*}}{\partial W_{B}}>0 \Leftrightarrow W_{A}^{\frac{\rho \square 1}{\rho}}>W_{B}^{\frac{\rho \nsupseteq 1}{\rho}} .
$$

The latter is always satisfied. $\frac{\partial S_{A}^{*}}{\partial W_{A}}$ is necessarily positive for $\leq \rho$. For $>\rho$, we need to invoke the second order condition for equilibrium existence: we saw that it can be approximated by: $\pi_{A}^{*} \square \pi_{B}^{*}<1 /$ in the proof of Proposition 1. Substituting for $\pi_{B}^{*}$, this condition becomes: $\pi_{A}^{*}<\frac{1}{2}(1+\underline{1})$. Since $\rho>1$, condition garantees that $\frac{\partial S_{A}^{*}}{\partial W_{A}}>0$.

Next,

$$
\frac{\partial S_{B}^{*}}{\partial W_{B}} \propto W_{A}^{\frac{\rho \square 1}{\rho}}(\rho+)+W_{B}^{\frac{\rho \square 1}{\rho}}(\rho \square \quad) \text { and } \frac{\partial S_{B}^{*}}{\partial W_{A}} \propto W_{B}^{\frac{\rho \square 1}{\rho}} \square W_{A}^{\frac{\rho \square 1}{\rho}},
$$

where the former is always positive and the latter always negative.

Proof of Proposition 1. We are focusing on pure strategies. Even when the pure strategy equilibrium does not exist, there must be a mixed strategy equilibrium (MSE), since payoff functions are continuous and bounded above. We are not interested in such MSE, because they are not realistic in our context.

Differentiating the probability of winning (1) with respect to an individual contribution $s_{P}^{i}$ yields:

$$
\begin{aligned}
\pi_{A}^{\prime} & \equiv \frac{\partial \pi_{A}}{\partial s_{A}^{i}}=\frac{S_{A}}{\pi_{A}}\left(1 \square \pi_{A}\right)=\overline{S_{A}} \pi_{A} \pi_{B} \text { and }, \\
\pi_{B}^{\prime} & \equiv{\overline{S_{B}}}_{A} \pi_{B} .
\end{aligned}
$$

Plugging (19) and (20) into (5), then taking the ratio between $S_{A}$ and $S_{B}$ shows that $\frac{S_{A}}{S_{B}}=$ $\left(\frac{W_{A}}{W_{B}}\right)^{\frac{\rho \boxminus 1}{\rho}}$ in a pure strategy equilibrium. Substituting for $S_{B}$ when we solve for the equilibrium 
value of $S_{A}$ as a function of the parameters $W_{A}, W_{B}$, and , we have:

$$
\begin{aligned}
S_{A} & =W_{A} \times\left(\pi_{A}^{\prime}\right)^{1 /(\rho \square 1)}=W_{A} \times\left(\frac{S_{A}}{S_{A}} \times \frac{S_{B}}{S_{A}+S_{B}} \times \frac{S_{A}}{S_{A}+S_{B}}\right)^{1 /(\rho \square 1)} \\
& =W_{A} \times\left(\frac{\left(S_{A}\left(W_{B} / W_{A}\right)^{\frac{\rho \square 1}{\rho}}\right)}{S_{A}} \times \frac{S_{A}+\left(S_{A}\left(W_{B} / W_{A}\right)^{\frac{\rho \square 1}{\rho}}\right)}{S_{A}+\left(S_{A}\left(W_{B} / W_{A}\right)^{\frac{\rho \square 1}{\rho}}\right)}\right)^{\frac{1}{\rho \square 1}} \\
& =W_{A} \times\left(\frac{\left(\left(W_{B} / W_{A}\right)^{\frac{\rho \square 1}{\rho}}\right)}{S_{A}} \times \frac{1}{\left(1+\left(\left(W_{B} / W_{A}\right)^{\frac{\rho \square 1}{\rho}}\right)\right)^{2}}\right)^{\frac{1}{\rho \square 1}}=W_{A} \times\left(\frac{1}{S_{A}} \times \omega\right)^{\frac{1}{\rho \square 1}}=\left(\omega W_{A}^{\rho \square 1}\right)^{\frac{1}{\rho}} .
\end{aligned}
$$

$S_{B}^{*}$ is derived following the same steps, and from the fact that $\frac{x^{y}}{\left(1+x^{y}\right)^{2}}=\frac{x^{\square} y}{\left(1+x^{\square}\right)^{2}}$. The latter implies that $\omega$ is identical for $A$ and for $B$.

Second, equilibrium existence of a pure strategy equilibrium depends on the second order conditions being satisfied for this vector of total contributions. After some simplifications, the SOC for type- $A$ donors can be expressed as:

$$
\square \frac{\pi_{A}^{*} \pi_{B}^{*}}{S_{A}^{2}}\left(1+\left(\pi_{A}^{*} \square \pi_{B}^{*}\right)\right)<(\rho \square 1) \frac{\left.s_{A}^{i}\right)^{\rho \square 2}}{\left(y^{i}\right)^{\theta}},
$$

which is always satisfied since $\pi_{A}^{*} \geq \pi_{B}^{*}$. A similar condition must hold for $B$ donors: ${ }^{38}$

$$
\frac{\pi_{A}^{*} \pi_{B}^{*}}{S_{B}^{2}}\left(1+\left(\pi_{B}^{*} \square \pi_{A}^{*}\right)\right)<(\rho \square 1) \frac{\left.q_{B}^{i}\right)^{\rho \square 2}}{\left(y^{i}\right)^{\theta}} .
$$

Noting that $\pi_{A}^{*} \pi_{B}^{*}=\omega$, we can rewrite this condition as follows:

$$
\begin{gathered}
\omega\left(\left(\pi_{A}^{*} \square \pi_{B}^{*}\right) \square 1\right)<(\rho \square 1) \frac{\left.\left(y^{i}\right)^{\theta} \pi_{B}^{\prime}\right)^{1 \square \frac{1}{\rho \square 1}}}{\left(y^{i}\right)^{\theta}} S_{B}^{2}=(\rho \square 1) \frac{\left(\pi_{B}^{\prime}\right)^{1 \square \frac{1}{\rho \square 1}}}{\left(y^{i}\right)^{\frac{\theta}{\rho \square 1}}}(\omega)^{\frac{2}{\rho}} W_{B}^{\frac{2(\rho \square 1)}{\rho}} \\
\omega\left(\left(\pi_{A}^{*} \square \pi_{B}^{*}\right) \square 1\right)<(\rho \square 1) \frac{\left(\frac{\omega}{S_{B}}\right)^{1 \square \frac{1}{\rho \square 1}}}{\left(y^{i}\right)^{\frac{\theta}{\rho \square 1}}}(\omega)^{\frac{2}{\rho}} W_{B}^{\frac{2(\rho \square 1)}{\rho}} \\
\omega\left(\quad\left(\pi_{A}^{*} \square \pi_{B}^{*}\right) \square 1\right)<(\rho \square 1) \frac{\left(\left(\omega / W_{B}\right)^{\frac{\rho \square 1}{\rho}}\right)^{1 \square \frac{1}{\rho \square 1}}}{\left(y^{i}\right)^{\frac{\theta}{\rho \square 1}}}(\omega)^{\frac{2}{\rho}} W_{B}^{\frac{2(\rho \square 1)}{\rho}}=(\rho \square 1) \frac{\omega W_{B}}{\left(y^{i}\right)^{\frac{\theta}{\rho \square 1}}} \\
(\square 1 \geq) \quad\left(\pi_{A}^{*} \square \pi_{B}^{*}\right) \square 1<(\rho \square 1) \frac{\left.\left.\sum n_{P} f_{P} \square y^{j}\right)^{\square} y^{i}\right)^{\frac{\theta}{\rho \square 1}}}{\left(y^{i}\right)^{\frac{\theta}{\rho \square 1}}}(>\rho \square 1) .
\end{gathered}
$$

\footnotetext{
${ }^{38}$ Second order condition amounts to looking at different points of the contest function for $A$ and for $B$ donors. Since $A$ donors perceive a higher winning probability than $B$, their SOC is automatically satisfied: they are in the concave part of the CSF. Instead, $B$ donors may be in a spot in which the CSF is convex. That is, a slight decrease in their contribution base would also decrease their individucal incentives to contribute. For sufficiently high values of , this would reinforce the drop in individual incentives so markedly that total contributions may be driven to 0 . In that case, there is no pure strategy equilibrium. The proposition shows that this can never happen if is no larger than $\rho$, or -for largerif the contribution bases are not too asymmetric.
} 
This is automatically satisfied for $\rho \geq \quad$ (since $\pi_{A}^{*} \square \pi_{B}^{*} \leq 1$ ), and when $\pi_{A}^{*} \square \pi_{B}^{*} \leq 1 /$ for any other value of $\rho$ and .

Proof of Proposition 2. Remember that $\left.\left.W_{P} \equiv\left(v_{P}\right) n_{P} \quad \sum_{i=1}^{G} f_{P} y^{i}\right) \times y^{i}\right)^{\theta}$. A meanpreserving spread of the income distribution is such that $\left.\left.\sum_{i<\bar{y}_{P}} \Delta f_{P} y^{i}\right) \times y^{i}=\square \sum_{i>\bar{y}_{P}} \Delta f_{P} y^{i}\right) \times$ $y^{i}$, where $\bar{y}_{P}$ is the subgroup with mean income in group $P$, and $\left.\Delta f_{P} y^{i}\right)$ is the change in density of each income class. If and only if $\theta>1$, this implies that $\left.\left.\mid \sum_{i<\bar{y}_{P}} \Delta f_{P} y^{i}\right) \times y^{i}\right)^{\theta} \mid<$ $\left.\left.\mid \sum_{i>\bar{y}_{P}} \Delta f_{P} y^{i}\right) \times y^{i}\right)^{\theta} \mid$ and hence that $W_{P}$ increases. Applying the proof of Lemma 1 in the appendix then demonstrates the result.

Proof of Proposition 3. First, we show that, for any given level of total contributions $S_{A}$ and $S_{B}$, the marginal return of contributing to $A$ is larger than that of contributing to $B$ iff $S_{A}<S_{B}$ :

$$
\begin{aligned}
\frac{\partial \pi_{A}}{\partial S_{A}} & =\square \pi_{A}^{2}(\square)\left(S_{A} / S_{B}\right)^{\square} \square 1(1 \square \alpha) S_{A} / S_{B} \frac{1}{S_{A}} \\
& =\pi_{A}^{2}\left(\left(S_{A} / S_{B}\right)^{1 \square \alpha}\right)^{\square}(1 \square \alpha) \frac{1}{S_{A}} \\
& =\pi_{A} \pi_{B}(1 \square \alpha) \frac{1}{S_{A}} \\
\frac{\partial \pi_{B}}{\partial S_{B}} & =\frac{\pi_{A} \pi_{B}}{S_{B}}
\end{aligned}
$$

and hence $\frac{\partial \pi_{A}}{\partial S_{A}}>\frac{\partial \pi_{B}}{\partial S_{B}}$ iff $S_{A}<S_{B}$.

Next, remember that $y^{i} \in[y, \bar{y}]$ with $y>0$ and $\bar{y}$ positive and finite, and that we are still focusing on the case $\rho=2$. In that case, there exist two cutoffs $s_{0}$ and $s_{1}$ for the cap on individual contributions $\bar{s}$, such that: $\forall \bar{s}>s_{1}$, no small donor is constrained and $\forall \bar{s}<s_{0}$ all small donors are constrained. By Proposition 1, for $\bar{s}>s_{1}$, the ratio of total small contributions must be:

$$
\frac{S_{A}^{*}}{S_{B}^{*}}=\left(\frac{W_{A}}{W_{B}}\right)^{\frac{1}{2}}=\left(\frac{n_{A}}{n_{B}}\right)^{\frac{1}{2}}
$$

and winning probabilities are the ones in Proposition 1:

$$
\pi_{A}^{*}=1 /\left(1+\left[\left(\frac{n_{A}}{n_{B}}\right)^{\frac{1}{2}}\right]^{\square}\right) .
$$

For $\bar{s}<s_{0}$, all small donors contribute $\bar{s}$. Therefore, $S_{A}=n_{A} \bar{s}$ and $S_{B}=n_{B} \bar{s}$. The contribution ratio is then $\frac{n_{A}}{n_{B}}$, and it is immediate to derive that $A$ 's winning probability is then

$$
\left.\pi_{A}^{0}=1 / \quad 1+\left[\frac{n_{A}}{n_{B}}\right]^{\square}\right) .
$$

For $\bar{s} \in\left(s_{0}, s_{1}\right), S_{A}$ must always be strictly larger than $S_{B}$, otherwise, individual best responses would be such that $\left.\left.s_{A}^{*} y^{i}\right) \geq s_{B}^{*} y^{i}\right), \forall y^{i}$, which would in turn imply $S_{A}>S_{B}$, a contradiction

If follows that: 
(1) there is a (possibly empty) set of income levels $y^{i}$ such that neither $A$ nor $B$-donors are capped: $s_{A}^{i}<s_{B}^{i}$

(2) there is a non-empty set of income levels $y^{i}$ such that $A$-donors are uncapped and $B$-donors are capped: $s_{A}^{i}<s_{B}^{i}=\bar{s}$

(3) there is a (possibly empty) set of income levels $y^{i}$ such that both $A$ and $B$-donors are capped, $s_{A}^{i}=s_{B}^{i}=\bar{s}$.

Parts (1) and (2) imply that $\pi_{A}(\bar{s})$ must be strictly less than $\pi_{A}^{0}$. The fact that proportionately more $B$-donors than $A$-donors are capped when $\bar{s}>s_{0}$ implies that their joint contribution capacity is reduced more than $A$ 's. This amounts to letting $W_{B}$ drop because of a reduction in top $B$ incomes. Following Proposition 1, this increases $\pi_{A}(\bar{s})$ above $\pi_{A}^{*}$. The proof of non-monotonicity is provided by the example in the main text.

Proof of Proposition 4. Define $y_{A}^{i}=k y_{B}^{i} \forall i=1, \ldots, G$, and order income groups such that $y_{P}^{i}<y_{P}^{i+1}$. Remember that, for any two donors $i$ and $j$ who support the same candidate and are unconstrained by the cap, we must have: $\left.s_{P} y_{P}^{i}\right) / s_{P}\left(y_{P}^{j}\right)=\left(y_{P}^{i} / y_{P}^{j}\right)^{\theta}$. The equilibrium is thus fully characterized by two income cutoff levels $\bar{y}_{A}(\bar{s})$ and $\bar{y}_{B}(\bar{s})$ and two "lowest contribution levels" $\left.s_{A} \quad y_{A}^{1}\right)$ and $\left.s_{B} \quad y_{B}^{1}\right)$ such that:

$$
\begin{aligned}
& \text { for } \left.\left.\left.y_{P}^{i}<\bar{y}_{P}(\bar{s}), s_{P} y_{P}^{i}\right)=s_{P} y_{P}^{1}\right) y_{P}^{i} / y_{P}^{1}\right)^{\theta}, \\
& \text { for } \left.y_{P}^{i}>\bar{y}_{P}(\bar{s}), s_{P} y_{P}^{i}\right)=\bar{s} .
\end{aligned}
$$

First, we show that $s_{A} y_{A}^{i}$ ) > $>s_{B} y_{B}^{i}$ ) for all unconstrained donors of some income group $i$, and hence that more $A$ - than $B$-donors will be constrained. To prove this, note that a necessary condition for the fraction of constrained $A$-donors to be smaller than that of $B$-donors is to have $\bar{y}_{A}(\bar{s})>k \bar{y}_{B}(\bar{s})$. This would require that $s_{B}\left(\bar{y}_{B}(\bar{s})\right)>s_{A}\left(k \bar{y}_{B}(\bar{s})\right)=k^{\theta} s_{A}\left(\bar{y}_{B}(\bar{s})\right)$, and hence $\left.\left.s_{B} y^{i}\right)>k^{\theta} s_{A} y^{i}\right)$ for any $y^{i}<\bar{y}_{B}(\bar{s})$. But this leads to a contradiction: such contributions would aggregate into $Q_{A}(\bar{s})<Q_{B}(\bar{s})$, which would produce best-response contributions $s_{B}\left(\bar{y}_{B}(\bar{s})\right)<$ $s_{A}\left(k \bar{y}_{B}(\bar{s})\right)$, because of free riding.

This establishes that $\left.s_{A} \quad y_{A}^{i}\right) \geq s_{B} \quad y_{B}^{i}$ ) for all $i=1, \ldots, G$, and the inequality must be strict for some $i$. Then, following the same steps as for the proof of Proposition 3 leads to Proposition 4 .

Proof of Proposition 5. First, we note that (7) can be rewritten as:

$$
\tilde{S}_{P}=(1+m) S_{P} .
$$

Plugging that into candidate $A$ 's probability of winning, we get:

$$
\begin{aligned}
\pi_{A}(\tilde{\mathbf{S}}) & \left.=1+\left[\frac{(1+m) S_{A}}{(1+m) S_{B}}\right]^{\square}\right)^{\square 1}, \\
& \left.=1+\left[\frac{S_{A}}{S_{B}}\right]^{\square}\right)^{\square 1}=\pi_{A}(\mathbf{S})
\end{aligned}
$$


As a consequence, incentives, and therefore the equilibrium, are the same for any $m \lessgtr 0$.

Proof of Proposition 6. With this tax, the cost of contributing $s_{P}^{i}$ for a donor with income $y^{i}$ becomes:

$$
\left.\left.\left.\left(s_{P}^{i}+\left[y^{i}\right)^{\theta / 2} \square 1\right] s_{P}^{i}\right)^{2} /\left[y^{i}\right)^{\theta} 2\right]=\square_{P}^{i}\right)^{2} / 2,
$$

which is independent of $y^{i}$.

\section{Appendix 2. Proofs for Section 4}

Proof of Proposition 7. Plugging (8) and (9) in the FOC (11), and rearranging, we obtain:

$$
\phi \beta R_{A}^{\beta \square 1} \square \frac{\sqrt{\frac{n_{B} \bar{Y}_{B}}{n_{A} \bar{Y}_{A}}} \lambda\left(R_{A}\right)}{1+\sqrt{\frac{n_{B} \bar{Y}_{B}}{n_{A} \bar{Y}_{A}}} \lambda\left(R_{A}\right)} \bar{\lambda}\left[\delta+\phi R_{A}^{\beta}\right] \square \frac{R_{A}}{\left(y^{l}\right)^{\theta}}\left(1+\sqrt{\frac{n_{B} \bar{Y}_{B}}{n_{A} Y_{A}}} \lambda\left(R_{A}\right)\right)=0 .
$$

$R_{A}^{*}$ is such that this condition is satisfied and the LHS is locally strictly decreasing in $R_{A}$. There is at least one solution to (22) because the LHS goes to $\infty$ when $R_{A} \rightarrow 0$, and goes to $\square \infty$ when $R_{A} \rightarrow \infty$. The equilibrium is generically unique because, even if there were multiple solutions to (22), the large donor would pick the global maximum.

Comparative statics follow. First, $R_{A}^{*}$ is strictly decreasing in $\delta$ : following an increase in $\delta$, the second term of (22) becomes more negative. Thus the LHS must increase to restore equality, which requires $R_{A}^{*}$ to decrease. The proof follows the same steps for $\bar{\lambda}, \frac{n_{B} \bar{Y}_{B}}{n_{A} \bar{Y}_{A}}$, and $y^{l}$.

Second, $R_{A}^{*}$ is strictly increasing in $\phi$. To prove this, note that (22) implies:

$$
\phi \beta R_{A}^{\beta \square 1} \square \frac{\sqrt{\frac{n_{B} \bar{Y}_{B}}{n_{A} Y_{A}}} \lambda\left(R_{A}\right)}{1+\sqrt{\frac{n_{B} \bar{Y}_{B}}{n_{A} \bar{Y}_{A}}} \lambda\left(R_{A}\right)} \bar{\lambda} \phi R_{A}^{\beta}>0,
$$

since the LHS of this expression amounts to adding strictly positive terms to (22). Hence, an increase in $\phi$ must increase the LHS of (22), implying that the LHS must decrease to restore equality. This requires $R_{A}^{*}$ to increase.

Proof of Proposition 8. Start from the equilibrium vector of contributions: $\left\{R_{A}^{*}, S_{A}^{*}, S_{B}^{*}\right\}$, with $S_{B}^{*}=\sum_{g} n_{B}^{g} s_{B}^{*}\left(y^{g} ; R_{A}\right)$. Since $S_{B}^{*}<S_{A}^{*}$, we have that $s_{B}^{*}\left(y^{g}\right)>s_{A}^{*}\left(y^{g}\right), \forall g$. The sum of these contributions determine the winning probability:

$$
\pi_{A}^{*}=\left(1+\left(S_{B}^{*} / S_{A}^{*}\right)\right)^{\square 1}(>1 / 2) .
$$

In the absence of a cap on individual contributions, the response of these $S_{P}^{*}$ with respect to $R_{A}$ is:

$$
\frac{\partial S_{P}^{*}}{\partial R_{A}}=\sum_{g} n_{P}^{g} \frac{\partial s_{P}^{*}\left(y^{g} ; R_{A}\right)}{\partial R_{A}}
$$

with $\frac{\partial s_{B}^{*}\left(y^{g} ; R_{A}\right)}{\partial R_{A}}>0$. In the proof of Proposition 7, we found that the stronger these responses, the less the large donor to $A$ contributes in equilibrium. 
Now, set the cap on individual contributions at $\bar{s}=s_{B}^{*} y^{G}$ ), such that, at $R_{A}=R_{A}^{*}$, this cap does not modify small donor contributions. Yet, $n_{B}^{G}$ donors now have a response $\left.\partial s_{B} \quad y^{G}\right) / \partial R_{A}=$ 0 for any $R_{A}>R_{A}^{*}$. Hence $\frac{\partial S_{B}^{*}}{\partial R_{A}}$ drops by a discrete amount, proportional to $n_{B}^{G}$. This reduces the marginal cost of $R_{A}$ by the same discrete amount (this corresponds to a discrete drop in $\bar{\lambda}$ in (22)). Accordingly, $R_{A}^{*}$ must increase discontinuously.

Proof of Proposition 10. The FOC of the large donor to $A$ is:

$$
\left.R_{A}^{2}=\alpha \delta^{\square} y^{l}\right)^{\theta} \frac{\left[\left(\frac{R_{A}}{R_{B}}\right)^{\alpha}\left(\frac{W_{A}}{W_{B}}\right)^{\frac{1 \square \alpha}{2}}\right]^{\square}}{\left.1+\left[\left(\frac{R_{A}}{R_{B}}\right)^{\alpha}\left(\frac{W_{A}}{W_{B}}\right)^{\frac{1 \square \alpha}{2}}\right]^{\square}\right)^{2}} .
$$

Note that, when $R_{A}$ tends to 0 , the LHS tend to 0 and the RHS tends to infinity. When $R_{A}$ tends to infinity, the LHS tends to infinity and the RHS tends to 0 . This directly implies that $R_{A}^{*}>0$.

After some simple but tedious manipulation, (23) becomes

$$
\left.\alpha \delta y^{l}\right)^{\theta} \quad\left[\left(\frac{1}{R_{B}}\right)^{\alpha}\left(\frac{W_{A}}{W_{B}}\right)^{\frac{1 \square \alpha}{2}}\right]^{\square}=R_{A}^{2}\left(R_{A}^{\alpha \gamma}+\left[\left(\frac{1}{R_{B}}\right)^{\alpha}\left(\frac{W_{A}}{W_{B}}\right)^{\frac{1 \square \alpha}{2}}\right]^{\square}\right)^{2} .
$$

Note that the LHS does not depend on $R_{A}$ and the RHS increases in $R_{A}$. Hence, $R_{A}^{*}$ is strictly increasing in $\delta$ and $\left.y^{l}\right)^{\theta}$

We now want to determine the effect of $W:=\left(\frac{W_{A}}{W_{B}}\right)^{\frac{1 \square \alpha}{2}}$ on $R:=\frac{R_{A}}{R_{B}}$. Let's rewrite (23) with this notation:

$$
R^{2}=\frac{\left.\alpha \delta y^{l}\right)^{\theta}}{R_{B}^{2}} \frac{\left[R^{\alpha} W\right]^{\square}}{\left(1+\left[R^{\alpha} W\right]^{\square}\right)^{2}} .
$$

which boils down to

$$
R=\sqrt{\frac{\alpha \delta\left(y^{l}\right)^{\theta}}{R_{B}^{2}} \frac{\left[R^{\alpha} W\right]^{\square}}{\left(1+\left[R^{\alpha} W\right]^{\square}\right)^{2}}} .
$$

Differentiating both sides with respect to $W$ obtains:

$$
\frac{\partial R}{\partial W}=\square \frac{1}{2} \frac{\frac{\alpha \gamma \delta\left(y^{l}\right)^{\theta}}{R_{B}^{2}} \frac{\left(R(R)^{\alpha}\right)+1}{(R)^{\alpha}+\alpha W(R)^{\alpha \square} R^{\prime}} \frac{1}{\left(\frac{1}{(W(R) \alpha)}+1\right)^{2}} \square 2 \frac{\alpha \gamma \delta\left(y^{l}\right)^{\theta}}{R_{B}^{2}} \frac{\left(W(R)^{\alpha}\right)\left(W(R)^{\alpha}\right)^{+1}}{(R)^{\alpha}+\alpha W(R)^{\alpha \square 1} R^{\prime}} \frac{1}{\left(\frac{1}{\left.(W(R))^{\alpha}\right)}+1\right)^{3}}}{\sqrt{\frac{\frac{\alpha \gamma \delta\left(y^{l}\right)^{\theta}}{R_{B}^{2}}}{\left(W(R)^{\alpha}\right)\left(\frac{1}{\left(W(R)^{\alpha}\right)}+1\right)^{2}}}}
$$

which boils down to

$$
\frac{\partial R}{\partial W}=\frac{R}{2} \frac{1 \square\left(W R^{\alpha}\right)^{\square}}{\left.1+\frac{\alpha}{2}+\left(W R^{\alpha}\right)^{\square} \quad 1 \square \frac{\alpha}{2}\right)}
$$

Note that $1 \square \frac{\alpha}{2}>0$ because $\leq 2$ and $\alpha<1$. The sign of $\frac{\partial R}{\partial W}$ is thus the same as that of 
$1 \square\left(W R^{\alpha}\right)^{\square}$. Hence, $R_{A}^{*}$ is decreasing in $W$ if and only if

$$
1<\left(W R^{\alpha}\right)^{\square},
$$

which boils down to

$$
\frac{R_{A}^{*}}{R_{B}}<\left(\frac{W_{B}}{W_{A}}\right)^{\frac{1 \square \alpha}{2 \alpha}} \text { or } \pi_{A}^{*}<1 / 2 .
$$

